Copyright (C1996, American Institute of Aeronautics and Astronautics, Inc.

AIAA Meeting Papers on Disc, January 1996

A9618460, NAS3-25812, AIAA Paper 96-0499

\title{
The pool boiling curve in microgravity
}

\author{
Ho S. Lee \\ Michigan Univ., Ann Arbor \\ Herman Merte, Jr. \\ Michigan Univ., Ann Arbor \\ Francis Chiaramonte \\ NASA, Lewis Research Center, Cleveland, $\mathrm{OH}$
}

\section{AIAA 34th Aerospace Sciences Meeting and Exhibit, Reno, NV Jan 15-18, 1996}

Pool boiling experiments using R-113 were conducted in the microgravity of space on a flat heater consisting of a semitransparent gold film sputtered on quartz substrate. Transient measurements of both the mean heater surface temperature and input heat flux are used to compute the mean heat transfer coefficient at the heater wall. Steady state pool boiling is achieved in microgravity under conditions in which a large vapor bubble somewhat removed from the heater surface is formed, which acts as a reservoir for the nucleating bubbles. The steady nucleate boiling heat transfer is enhanced materially in microgravity relative to that in Earth gravity, while the heat flux at which dryout occurs is considerably less. Using quasi-steady data obtained during periods in which some significant portions of the heater surface were dried out, it was possible to construct two distinct composite approximate microgravity pool boiling curves for R-113, one for the higher level of subcooling and one for the lower level of subcooling. (Author) 


\title{
AIAA-96-0499
}

\section{"THE POOL BOILING CURVE IN MICROGRAVITY"}

\author{
Ho Sung Lee \\ Herman Merte, Jr. \\ The University of Michigan \\ Department of Mechanical Engineering and Applied Mechanics \\ Ann Arbor, MI 48109-2125 \\ Francis Chiaramonte \\ NASA Lewis Research Center \\ Cleveland, OH 44135
}

\begin{abstract}
Pool boiling experiments using $\mathrm{R}-113$ were conducted in the microgravity of space on a flat heater, consisting of a semi-transparent gold film sputtered on quartz substrate, $19.05 \mathrm{~mm}$ x $38.1 \mathrm{~mm}(0.75$ " x 1.50"). Transient measurements of both the mean heater surface temperature and input heat flux are used to compute the mean heat transfer coefficient at the heater wall. Steady state pool boiling is achieved in microgravity under conditions in which a large vapor bubble somewhat removed from the heater surface is formed, which acts as a reservoir for the nucleating bubbles. The steady nucleate boiling heat transfer is enhanced materially in microgravity relative to that in earth gravity, while the heat flux at which dryout occurs is considerably less. Using quasi-steady data obtained during periods in which some significant portions of the heater surface were dried out it was possible to construct two distinct composite approximate microgravity pool boiling curves for R-113, one for the higher level of subcooling and one for the lower level of subcooling. These are compared with a Reference Curve for pool boiling at $a / g=+1$, constructed from all available data correlations deemed to reasonably represent the circumstances present.
\end{abstract}

\section{Nomenclature}

$P_{\text {sys }} \quad$ : System pressure

$q_{T}^{\prime \prime} \quad:$ total heat flux applied

$\mathrm{t} \quad$ : time

$t^{*} \quad$ :delay time between onset of heating and nucleation

$T \quad$ : temperature

$T_{\text {bulk }} \quad$ : bulk temperature

$T_{\text {sat }} \quad$ : saturation temperature

$T_{w}^{*} \quad$ : mean heater surface temperature at nucleation

$\Delta T_{w}^{*} \quad$ : mean heater surface superheat at nucleation

$\Delta T_{w} \quad$ : steady mean heater surface superheat

$\Delta T_{\text {sub }} \quad$ : bulk liquid subcooling

\section{Introduction}

Pool boiling can be viewed as the lower limit of forced convection boiling in microgravity, and should be reasonably well understood, in terms of describing its behavior, as an initial step toward understanding the velocity effects on boiling. This can lead to an improved description of forced convection boiling in earth gravity, not withstanding the current interest in its behavior in microgravity. A related intrinsic question with pool boiling in microgravity is whether a long term steady state can be attained. This becomes a ponderable issue in the absence of appropriate experimental demonstrations. Pool boiling has been studied extensively in earth gravity, and disagreements are still in evidence as to the true nature of the source of enhancement in heat transfer, whether due to latent heat transport, microconvection, or some combination. Since buoyancy performs a major role in pool boiling in earth gravity, its absence in microgravity understandably leads to speculation about other mechanisms coming to the forefront.

One of the difficulties in experimentation is that of producing a microgravity environment on earth. Prior experiments involving boiling in reduced gravity have been conducted and reported by Usiskin and Siegel ${ }^{15}$, Merte and $\mathrm{Clark}^{7}$, Siegel and Keshock ${ }^{11}$, Littles and Walls $^{6}$, Oker ${ }^{10}$, Straub et al. ${ }^{13}$, Ervin et al. ${ }^{3}$, Merte et al. ${ }^{8}$, and Abe et al. ${ }^{1}$, using various facilities; parabolic aircraft flights, sounding rockets, and free fall in drop towers. The results to date have been contradictory: Usiskin and Siegel ${ }^{15}$, Merte and Clark $^{7}$ and Straub et al. ${ }^{13}$ have indicated that nucleate boiling heat transfer appears to be insensitive to reductions in gravity, while the results presented by Littles and Walls ${ }^{6}, \mathrm{Oker}^{10}$, Abe et al. ${ }^{1}$ and Merte et al. ${ }^{8}$ demonstrate an enhancement of such boiling heat transfer in microgravity. It is believed that the geometry of the heater surface used is a major factor in the differences observed. In general, experiments conducted with wires indicate little or no change in nucleate boiling heat transfer in reduced gravity or microgravity compared to earth gravity, while 
flat surface heater surfaces tended to show somewhat of an improvement in microgravity. The study of boiling on a ribbon in a drop tower by Siegel and Keshock ${ }^{11}$ included both heat transfer measurements and high speed photography. Although the heat transfer results were inconclusive with respect to the effect of reduced gravity, the observations that the small vapor bubbles formed at the heater surface and absorbed by coalescence with larger bubbles hovering nearby lead to several possible conclusions that can only be confirmed by long-term experiments: The stirring action and turbulence induced by the growth of these small bubbles can provide good heat transfer performance even in the absence of buoyancy, and the removal of these small bubble by absorption by the larger ones can prevent dryout and sustain the mechanism of nucleate boiling in microgravity. The variable quality of the gravity in the works referred to above, as well as the short times available, render problematic the resolution of the apparent contradictions about the role of gravity up to the present.

The purpose of the present paper is to provide experimental data for pool boiling under relatively long periods of time under well-defined conditions using space flights. An attempt is made to describe the mechanisms of pool boiling in microgravity by means of photographic visualization, with due consideration to the effects of heater surface size. Pool boiling experiments were conducted on three (3) space flights, designated as PBE-IA-IB-IC on the STS-47, -57, and 60 , respectively, as part of the NASA Get Away Special (GAS) program, with each flight experiment consisting of nine different test runs, conducted during the period 1992 through 1994. The identical test runs were repeated in earth gravity following the space experiments so that direct comparisons could be obtained between the behavior in microgravity and in earth gravity.

\section{Experimental Apparatus and Procedure}

Measurements of heat transfer and various parameters associated with bubble growth dynamics were obtained in the microgravity of space, providing on the order of $\mathrm{a} / \mathrm{g} \sim 10^{-4}$, with $\mathrm{R}-113$. Nine test runs were conducted at three levels of heat flux $(2,4$ and 8 $\left.\mathrm{W} / \mathrm{cm}^{2}\right)$ and three levels of subcooling $(0,2.7$ and $11^{\circ} \mathrm{C}$ ), each lasting up to two minutes, in each of three space experiments, for a total twenty seven (27) test runs. Photographs of the boiling process were obtained simultaneously from the side and from beneath the heater surface at framing rates of 10 and $100 \mathrm{fps}$ with a $16 \mathrm{~mm}$ cine camera. The three space experiments were virtually identical, differing primarily in the speeds and lengths of the photography and heating times. The same hardware was used for PBE-IA and IC (STS-47 and 60 , respectively), while that of the PBE-IB (STS-57) was of the same construction. This provided opportunities for observations of repeatability and/or reproducibility.

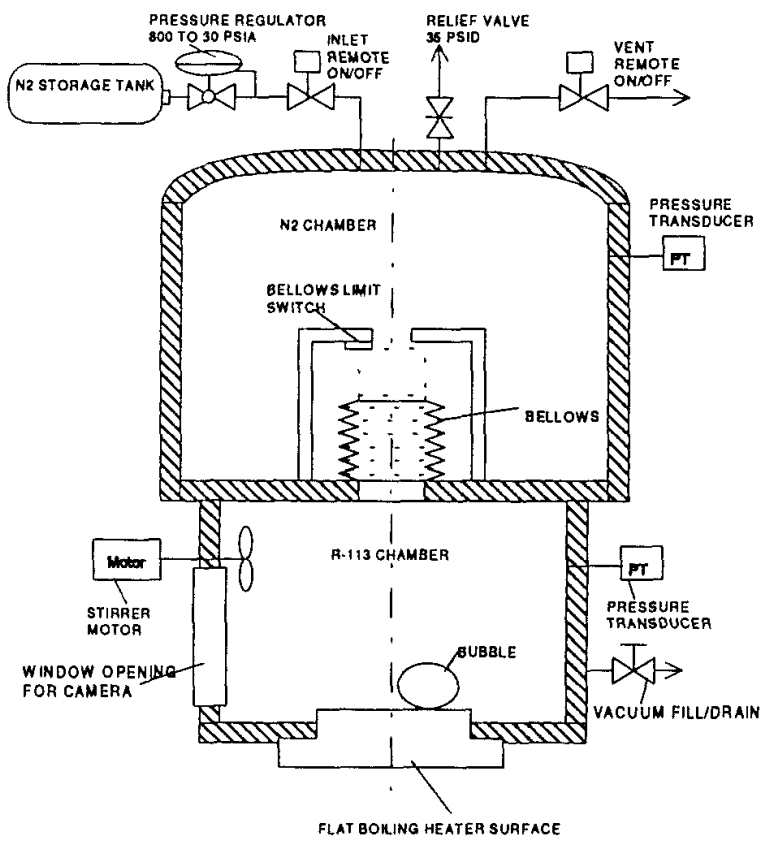

Figure 1. Schematic of test vessel with concepts to provide constant pressure and initially uniform fluid temperature.

\section{Test Vessel}

Figure 1 presents a schematic diagram of the test vessel, consisting of R-113 and nitrogen $\left(\mathrm{N}_{2}\right)$ chambers. The R-113 chamber has internal dimensions of $15.2 \mathrm{~cm}$ Dia. by $10.2 \mathrm{~cm}$ High, and includes a gold film heater on a quartz substrate, a pressure transducer, thermistors, and stirrer. The stirrer functions to provide a timely uniform fluid temperature between each test. The pressure transducer measures the system pressure with an uncertainty of $\pm 0.345 \mathrm{kPa}$, while thermistors measure the liquid temperatures adjacent to the heater surface at distances of $1,5,10 \mathrm{~mm}$, and at various other locations, with a total uncertainty of $\pm 0.06{ }^{\circ} \mathrm{C}$. The nitrogen chamber is used to maintain the desired system pressure. System subcooling is obtained by increasing the system pressure above the saturation pressure corresponding to the initial liquid temperature. In the absence of buoyancy, an initially motionless liquid remains stagnant upon heating until the onset of boiling, and the temperature distribution in the liquid at the onset of boiling can be determined from a conduction heat transfer analysis. 


\section{Heater Surfaces}

Two heater surfaces are placed on a single flat substrate, installed so as to form one wall of the test vessel as shown in Figure 1, with one acting as a backup. Each heater consists of a $400 \AA$ thick semitransparent gold film sputtered on a highly polished quartz substrate, seen in Figure 2, and serves simultaneously as a heater, with an uncertainty of $\pm 2 \%$ in the measurement of the heat flux, and a resistance thermometer, with an overall uncertainty of $\pm 1.0^{\circ} \mathrm{C}$. The heater is rectangular in shape, $19.05 \times 38.1 \mathrm{~mm}$ $(0.75 \times 1.5 \mathrm{inch})$. Degassed commercial grade R-113 (trichlorotrifluoroethane, $\mathrm{CCl}_{2} \mathrm{FCClF}_{2}$ ) was used because of its low normal boiling point $\left(47.6{ }^{\circ} \mathrm{C}\right)$, which minimized problems associated with heat loss to the surroundings, and because of its electrical nonconductivity, which is compatible for direct contact with the thin gold film heater. Further experimental details may be found in Merte et al. (1995).

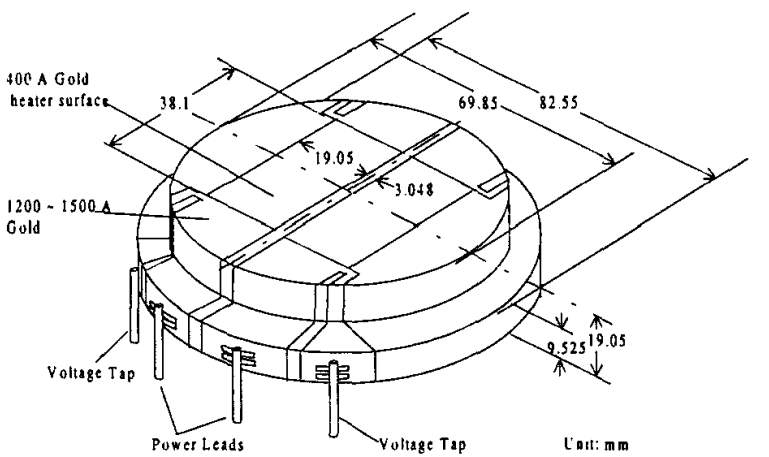

Figure 2. Transparent gold film heater/resistance thermometer on quartz substrate.

\section{Measurement of Mean Heater Surface Temperature}

Measurement of the electrical resistance across the heater surface provided the mean heater surface temperature as a function of time, with the aid of calibrations carried out prior to the experiments. These temperatures were filtered to remove noise effects, using a three consecutive point averaging technique, advancing sequentially one point at a time, which serves to smooth the data without eliminating physical behavior. The total heat flux input is transported into both the liquid and the quartz heater substrate, and the measured mean heater surface temperatures can be used to compute the heat flux to the quartz substrate using appropriate numerical computations. Subtracting this from the input heat flux provides the heat flux to the liquid and the transient mean heat transfer coefficient. The identical numerical method was applied consistently throughout the data analysis to compute the mean heat transfer coefficient, and it was demonstrated that a consistent relationship was maintained between the relative and absolute values of the heat transfer coefficients so computed. It will be noted below that although the heat flux to the liquid is used to compute the heat transfer coefficients, the total imposed heat flux is used as appropriate to distinguish between the different heat flux levels.

\section{Experimental Procedure}

When the desired uniform bulk liquid temperature in the test vessel is attained by the combination of the stirrer and electric heater strips on the exterior surfaces, the test run begins with activation of measurements of the various local fluid temperatures and pressure. Power to the thin film heater surface is activated at 10 seconds simultaneous with the camera unit, and results in the growth of a thermal boundary layer at the heater surface, up to the onset of boiling. The activation/deactivation of the heater, camera, and stirrer motor depend on the details of the specific test matrix, with a test run lasting up to 120 seconds. A fixed sampling rate of $10 \mathrm{~Hz}$ is employed to measure the mean heater surface temperature, system pressure and fluid temperatures throughout the experiments.

\section{Results and Discussion}

The present experiments represent a somewhat restricted number and combination of variables because of limitations in size, weight, power, and accessibility. Of the total of twenty seven (27) test runs conducted under microgravity, what can be termed steady state boiling was present in only thirteen (13), while the remainder exhibited a transient rise of heater surface temperature due to dryout. The present study focuses on the mechanisms of pool boiling in microgravity which govern whether steady state will exist, and the general circumstances which lead to dryout. This permits the establishment of a so-called microgravity pool boiling curve.

A visual comparison of typical pool boiling with the same heater surface in both earth gravity and microgravity is presented in Figure 3, where the upper half presents the side view and the lower half is the bottom view through the semi-transparent gold film heater. The bright spots in the lower left are the binary time indicators. The operating conditions are almost identical for both the normal gravity and reduced gravity. Vapor bubbles in earth gravity are observed to be quite small, compared to those in microgravity, because of buoyancy forces acting to remove the vapor bubbles from the vicinity of the heater surface. The numerous relatively larger bubbles in microgravity are uniformly distributed and attached to or in the vicinity of the heater surface. The mean heater surface superheats are $27^{\circ} \mathrm{C}$ in earth gravity and $18.1^{\circ} \mathrm{C}$ in 


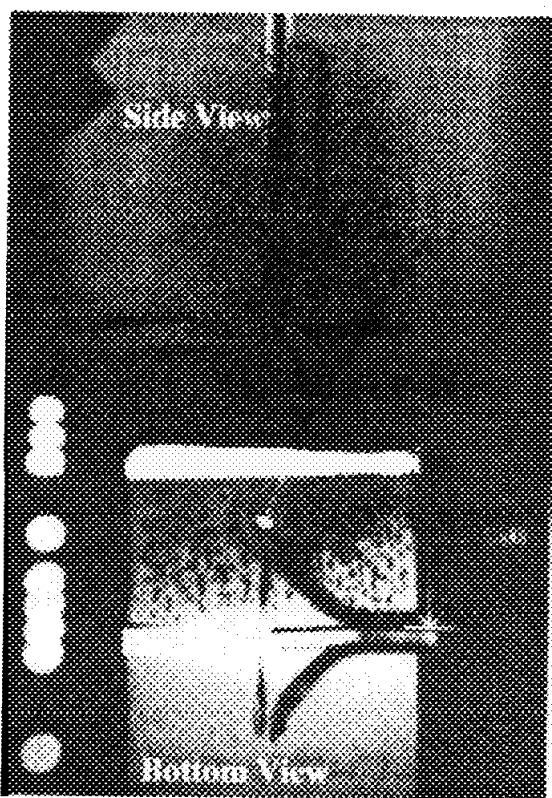

(a) Normal gravity $\mathrm{a} / \mathrm{g}=+1(\mathrm{t}=78.22 \mathrm{sec}$. $)$

$$
\begin{aligned}
& \text { Post flight (STS-60) Run \#2 } \\
& q_{T}^{\prime \prime}=3.6 \mathrm{~W} / \mathrm{cm}^{2}, \text { Psys }=150.1 \mathrm{kPa}, \\
& \Delta \mathrm{T}_{\mathrm{w}}=27^{\circ} \mathrm{C}, \Delta \mathrm{T}_{\text {sub }}=11.5^{\circ} \mathrm{C} .
\end{aligned}
$$

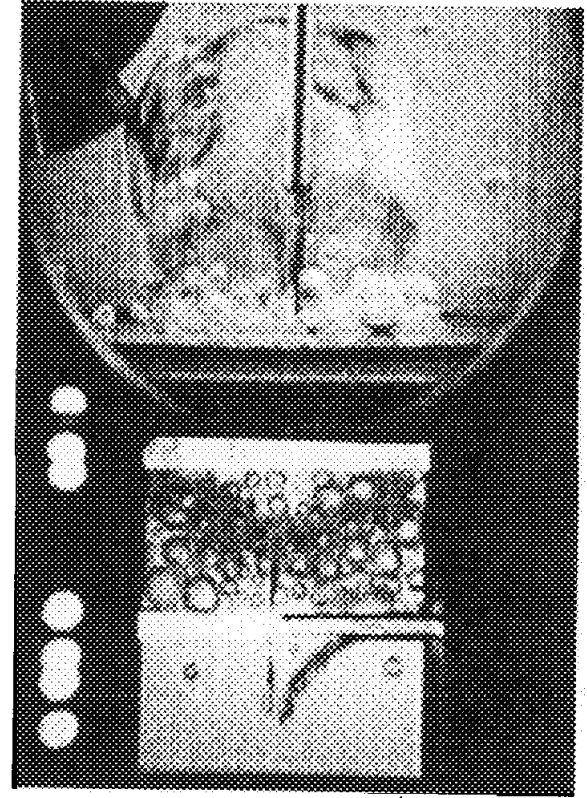

(b) Reduced gravity $\mathrm{a} / \mathrm{g}=10^{-4}(\mathrm{t}=61.47 \mathrm{sec})$

Space flight (STS-60) Run \#2.

$q_{T}^{\prime \prime}=3.6 \mathrm{~W} / \mathrm{cm}^{2}$, Psys $=145.9 \mathrm{kPa}$,

$\Delta \mathrm{T}_{\mathrm{w}}=18.1^{\circ} \mathrm{C}, \Delta \mathrm{T}_{\mathrm{sub}}=11.5^{\circ} \mathrm{C}$.

Figure 3. Visual comparison of pool boiling with R-113 on earth and during a space shuttle flight under otherwise similar conditions.

microgravity, which indicate an obvious enhancement of the heat transfer process in microgravity. This is presumed to be due to the evaporation of the larger liquid microlayer areas formed beneath the vapor bubbles in microgravity.

Measurements of the mean heater surface superheat with the derived mean heat transfer coefficient are presented in Figure 4 as a function of time for the cases shown in Figure 3. The measured mean heater surface superheats are observed to reach the steady state levels within 5 to 10 seconds following nucleation. These cases will be considered in more detail below by examining photographs and measurements of both the local fluid temperature in the vicinity of the heater surface and the system pressure. It is noted in Figure 4 that operation in a microgravity environment with these conditions results in an enhancement in the nucleate boiling heat transfer, manifested here by increase in the mean heat transfer coefficient from $\mathrm{h}=1250 \mathrm{~W} / \mathrm{m}^{2} \cdot \mathrm{K}$ at $\mathrm{a} / \mathrm{g}=+1$ to $\mathrm{h}=1650 \mathrm{~W} / \mathrm{m}^{2} \cdot \mathrm{K}$ at $\mathrm{a} / \mathrm{g}=10^{-4}$, an increase of about $32 \%$. The mean heater surface superheat in microgravity rises to $62.8{ }^{\circ} \mathrm{C}$ prior to nucleation by transient heat conduction, with a mean heat transfer coefficient of about $250 \mathrm{~W} / \mathrm{m}^{2} \cdot \mathrm{K}$. The attainment of such a high superheat at nucleation is believed to be a consequence of the smoothness of the heater surface, resulting in what might be termed homogeneous nucleation. The superheat curve in earth gravity, on the other hand, rises slowly to $37.4{ }^{\circ} \mathrm{C}$ due to natural convection, with a heat transfer coefficient of about 500 $\mathrm{W} / \mathrm{m}^{2} \cdot \mathrm{K}$, which is in good agreement with the correlation of natural convection.

The dynamic initial vapor bubble growth and subsequent steady pool boiling for the microgravity case in Figure 4 are presented photographically in Figures 5 and 6 , respectively. The rapid drop in the mean heater surface temperature, at the maximum rate of $33^{\circ} \mathrm{C} / \mathrm{sec}$, appears to be related to the evaporation of the thin liquid layer formed beneath the large bubble and the subsequent initial dynamic vapor bubble growth taking place, which impels the large vapor bubble away from the heater surface. Cooler liquid is then drawn beneath the large departing bubble, followed by the formation of new bubbles. These phenomena are shown in Figure 5 (A)-(D). The camera speed was not high enough to stop the vapor bubble motion, so that the bubble in Figure 5 (A) appears to be blurred. The bulk liquid pressure resulting from the dynamic growth is depicted in Figure 7 , where the peak pressure reaches $159.7 \mathrm{kPa}$ at 30.8 


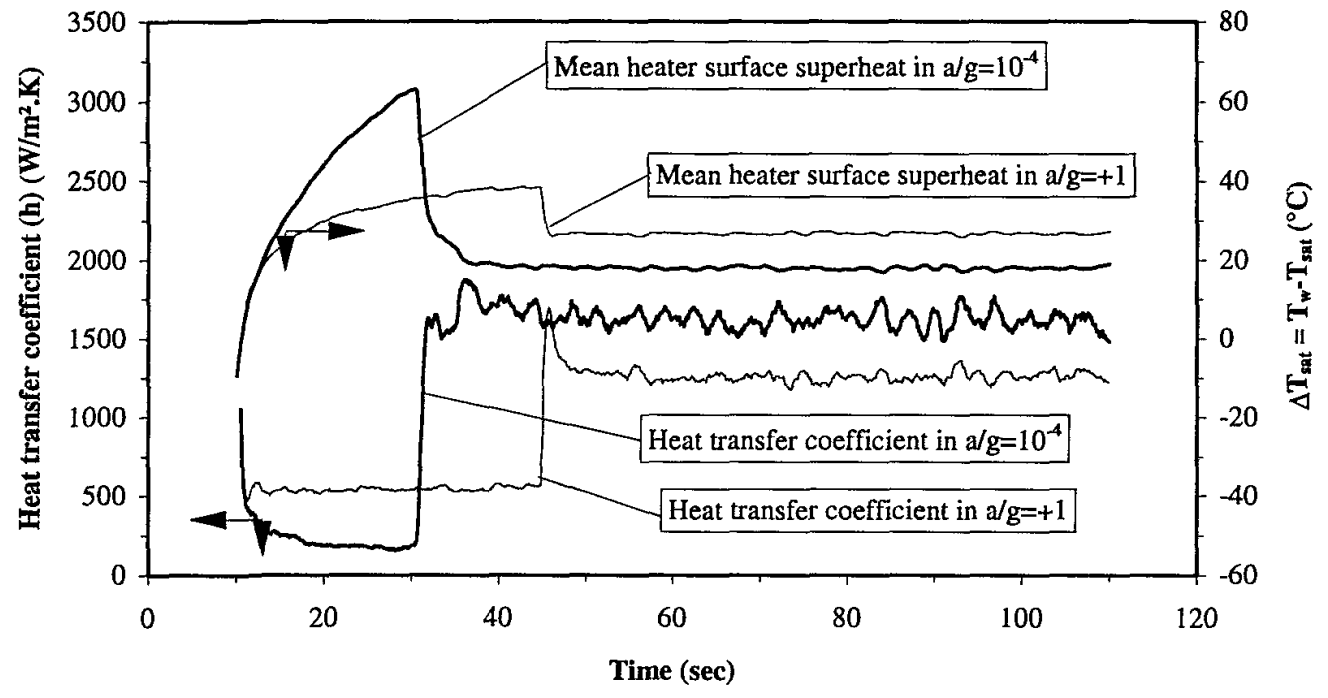

Figure 4. Comparison of measured mean heater surface superheats and derived heat transfer coefficients between STS-60 Run \#2 and Post flight (STS-60) Run \#2.

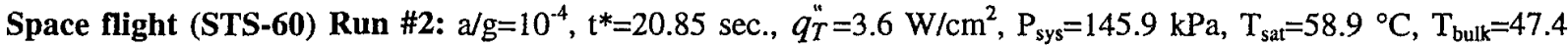
${ }^{\circ} \mathrm{C}, \mathrm{T}_{\mathrm{w}}=77^{\circ} \mathrm{C}, \Delta \mathrm{T}_{\mathrm{w}}=18.1^{\circ} \mathrm{C}, \Delta \mathrm{T}_{\text {sub }}=11.5^{\circ} \mathrm{C}$.

Post flight (STS-60) Run \#2: a/g $=+1, \mathrm{t}^{*}=35.08 \mathrm{sec} ., q_{T}^{\prime \prime}=3.6 \mathrm{~W} / \mathrm{cm}^{2}, \mathrm{P}_{\text {sys }}=150.1 \mathrm{kPa}, \mathrm{T}_{\text {sat }}=59.9^{\circ} \mathrm{C}, \mathrm{T}_{\text {bulk }}=48.4^{\circ} \mathrm{C}$, $\mathrm{T}_{\mathrm{w}}=86.9^{\circ} \mathrm{C}, \Delta \mathrm{T}_{\mathrm{w}}=27.0^{\circ} \mathrm{C}, \Delta \mathrm{T}_{\mathrm{sub}}=11.5^{\circ} \mathrm{C}$.

seconds, preceded and followed by a constant pressure of $146 \mathrm{kPa}$. It comes obvious that the pressure control system was not capable of responding to this disturbance. The absence of any pressure disturbance upon nucleation in earth gravity is also to be noted.

\section{Vapor Bubble Coalescence and Removal}

Figure 6 is a sequence of photographs of the steady state pool boiling process in microgravity following the initial dynamic vapor bubble growth of Figure 5, separated by intervals of about 10 seconds in order to present a more complete picture of pool boiling. What is notable here is that following nucleation the small bubbles grow at first by evaporation and then by coalescence with adjacent vapor bubbles, followed by sudden removal from the vicinity of the heater surface by coalescence with the large vapor bubble observed at the back edge of the heater. This is the bubble which was initially impelled away from the heater surface, and which now plays an important role in removing the newly formed vapor bubbles from the heater surface by surface tension, thereby inhibiting the onset of dryout of the heater surface. The cyclic repetition of the vapor bubble generation and coalescence process induces turbulence in the fluid adjacent to the heater surface, thereby enhancing the boiling heat transfer in microgravity. As pointed out above, a similar phenomenon was described by Siegel and Keshock ${ }^{11}$ for a single bubble coalescence in reduced gravity, although it was not possible to determine the enhancement quantitatively because of the short experimental periods available at that time. Because of limitations in the camera speed and film length associated with the automation of the experiment, it was not possible to determine the frequency of formation of the small vapor bubbles at the heater surface.

The local fluid temperature measurements $1 \mathrm{~mm}$ above the heater surface are shown in Figure 8 both at earth gravity and during the space flight for Run No.2, corresponding to Figures 3-7. These are expressed in terms of superheat, and the consistent bulk heating occurring in microgravity prior to nucleation is quite obvious, followed by oscillations between the saturation temperature corresponding to the system pressure of Figure 7 and a subcooling of approximately $2{ }^{\circ} \mathrm{C}$, representing the variations between the saturated vapor of the local bubbles and the bulk liquid being transported toward the heater surface. In earth gravity on the other hand, oscillations arise due to single phase natural convection prior to nucleation, followed by continuous oscillations between subcoolings of 6 and 9 ${ }^{\circ} \mathrm{C}$.

The coalescence of vapor bubbles at the heater surface in microgravity can be seen more readily at the lowest nominal heat flux level of $2 \mathrm{~W} / \mathrm{cm}^{2}$. The mean 


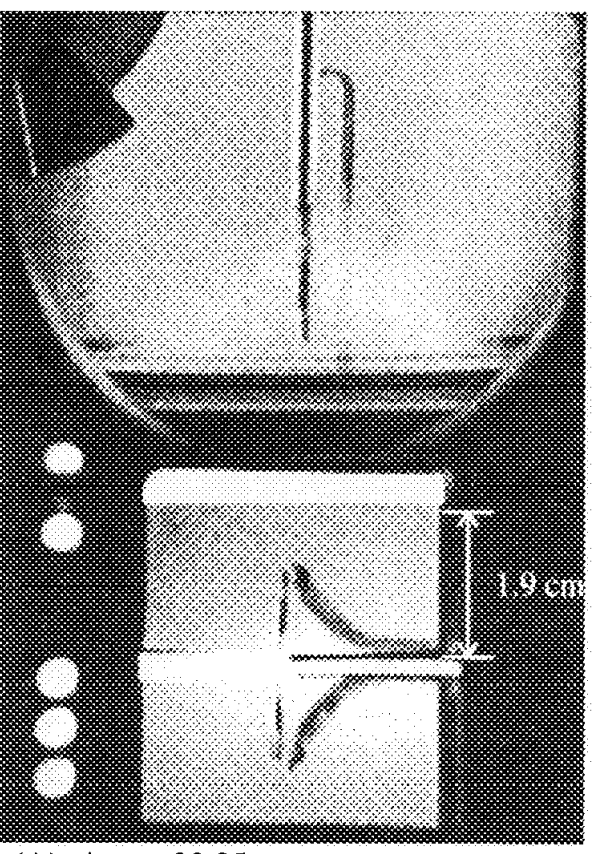

(A) time $=30.85 \mathrm{sec}$.

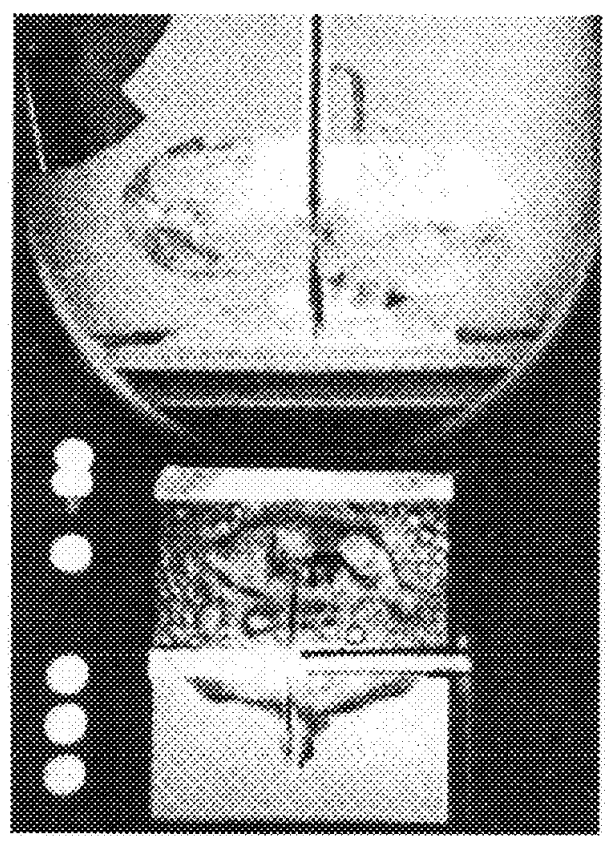

(C) time $=31.25 \mathrm{sec}$.

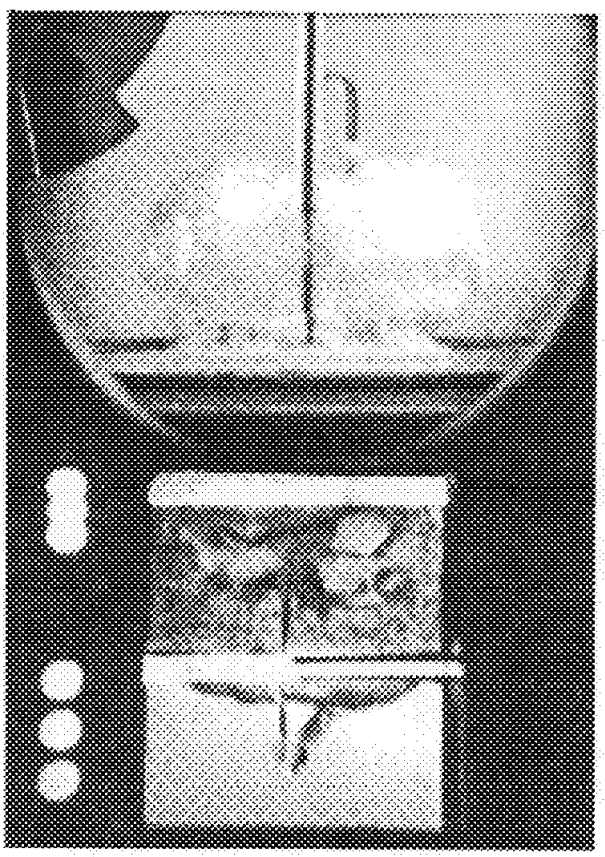

(B) time $=31.05 \mathrm{sec}$.

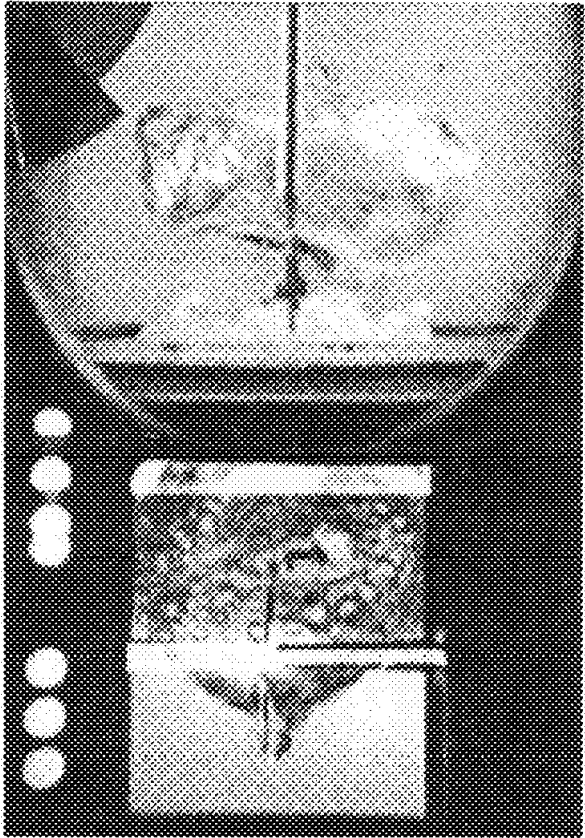

(D) time $=31.55 \mathrm{sec}$

Figure 5. Dynamic vapor bubble growth with R-113 in microgravity for STS-60 Run \#2.

$\mathrm{a} / \mathrm{g}=10^{-4}, \mathrm{t}^{*}=20.85 \mathrm{sec} ., q_{\mathrm{T}}^{\prime \prime}=3.6 \mathrm{~W} / \mathrm{cm}^{2}, \mathrm{P}_{\mathrm{sys}}=145.9 \mathrm{kPa}, \mathrm{T}_{\text {sal }}=58.9^{\circ} \mathrm{C}, \mathrm{T}_{\text {bulk }}=47.4^{\circ} \mathrm{C}, \mathrm{T}^{*}{ }_{\mathrm{w}}=122.7^{\circ} \mathrm{C}, \Delta \mathrm{T}^{*}{ }_{\mathrm{w}}=62.8^{\circ} \mathrm{C}$, $\Delta \mathrm{T}_{\mathrm{sub}}=11.5^{\circ} \mathrm{C}$. 
Copyright (c)1996, American Institute of Aeronautics and Astronautics, Inc.

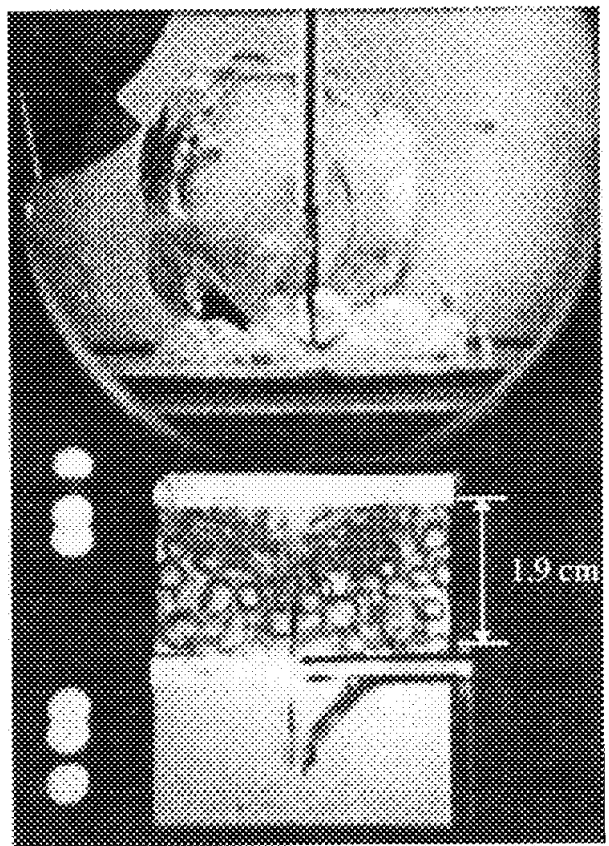

(A) time $=51.23 \mathrm{sec}$.

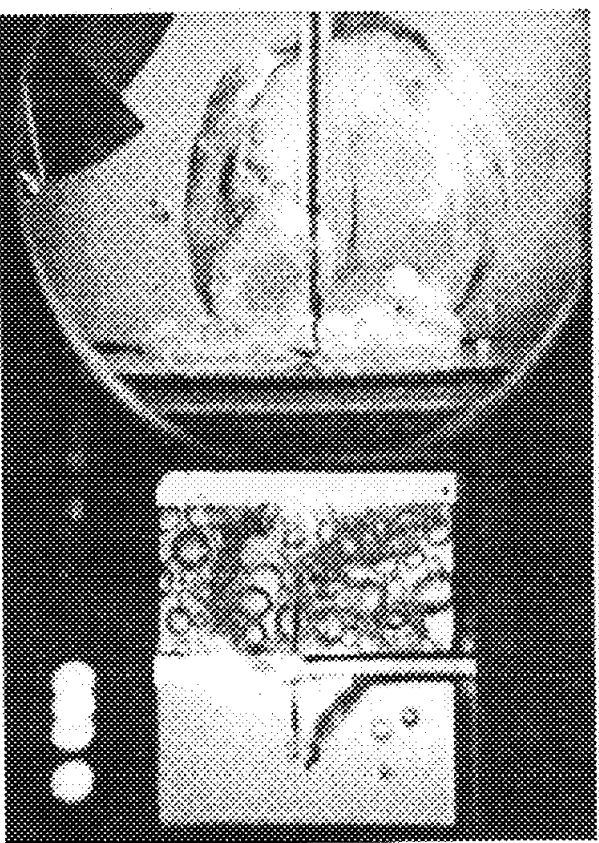

(C) time $=71.45 \mathrm{sec}$.

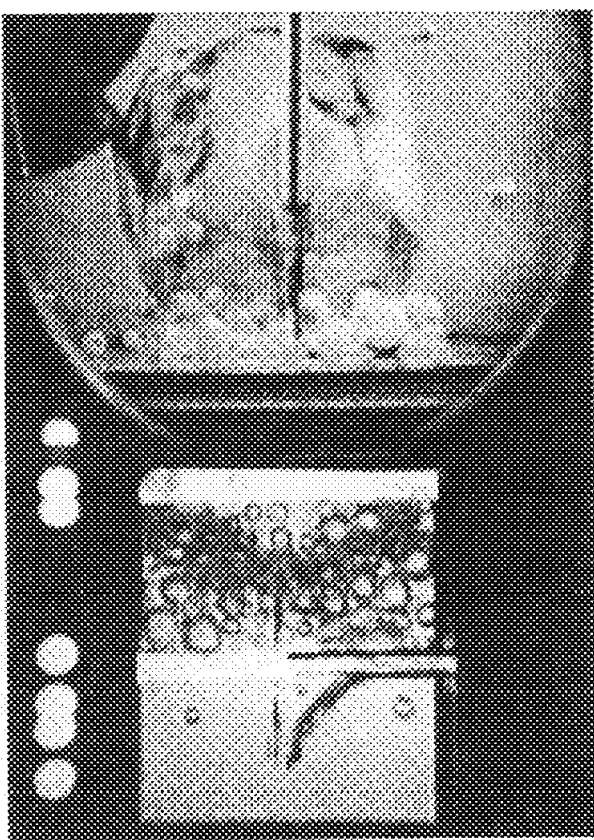

(B) time $=61.47 \mathrm{sec}$.

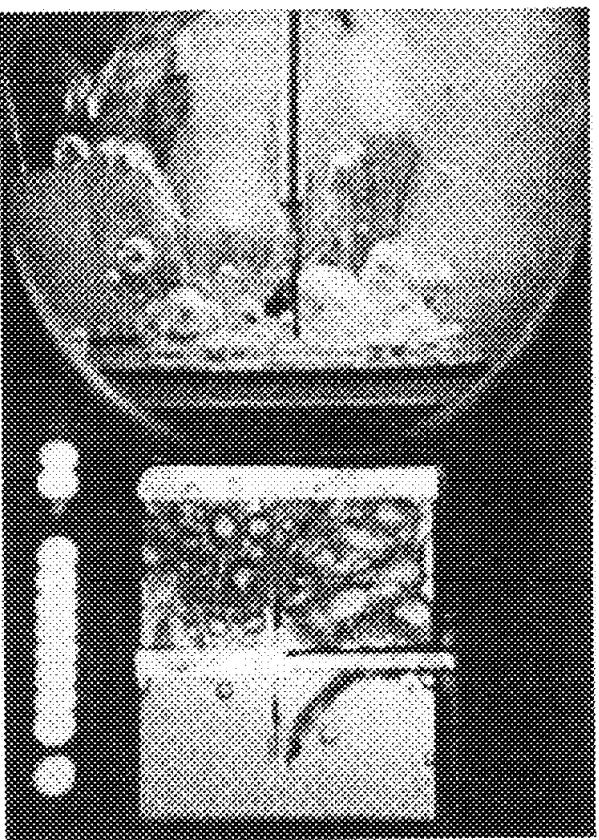

(D) time $=91.40 \mathrm{sec}$.

Figure 6. Steady pool boiling in microgravity for STS-60 Run \#2.

$\mathrm{a} / \mathrm{g}=10^{-4}, q_{T}^{\prime \prime}=3.6 \mathrm{~W} / \mathrm{cm}^{2}, \mathrm{P}_{\text {sys }}=145.9 \mathrm{kPa}, \mathrm{T}_{\text {sat }}=58.9^{\circ} \mathrm{C}, \mathrm{T}_{\text {bulk }}=47.4^{\circ} \mathrm{C}, \mathrm{T}_{\mathrm{w}}=77^{\circ} \mathrm{C}, \Delta \mathrm{T}_{\mathrm{w}}=18.1^{\circ} \mathrm{C}, \Delta \mathrm{T}_{\text {sub }}=11.5^{\circ} \mathrm{C}$. 


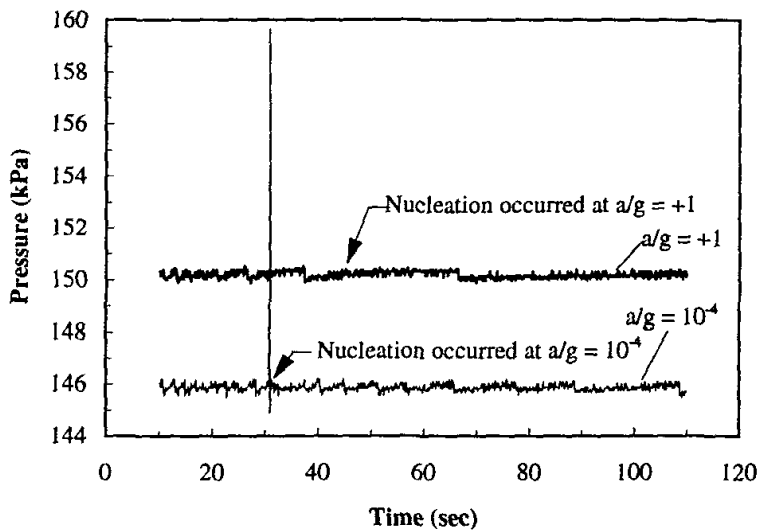

Figure 7. System pressure measurement for space flight STS-60 Run \#2 and Post flight (STS-60) Run \#2.

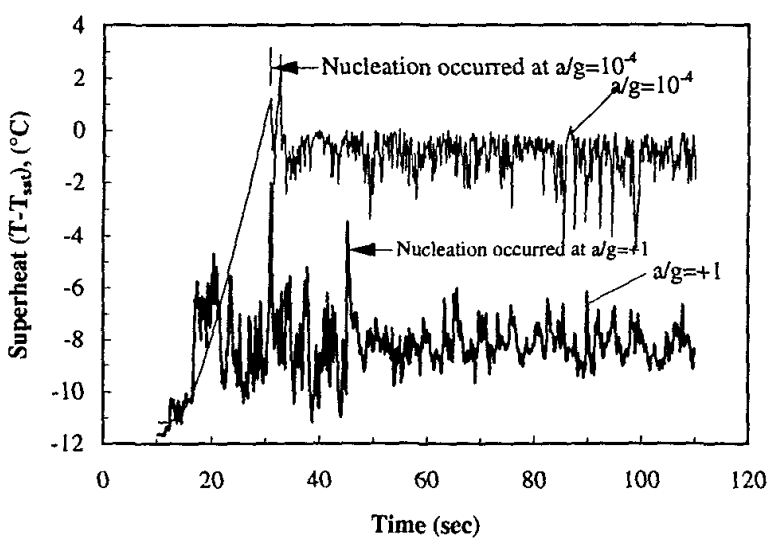

Figure 8. Local fluid superheat ( $T-T_{\text {sat }}$ ) measured at 1 $\mathrm{mm}$ above the heater surface for space flight STS-60 Run \#2 and Post flight (STS-60) Run \#2.

heater surface temperature and heat transfer coefficients are given in Figure 9 for STS-57 Run No.3, while the coalescence is illustrated visually in Figure 10. The photographs show several pairs of vapor bubbles coalescing on contact due to surface tension, increasing in size and reducing in number by half during a period of 0.06 seconds. The vapor bubbles attached to the heater surface undergo rapid movements as a result of the coalescence, inducing also corresponding motions in the fluid adjacent to the heater surface. These relatively large vapor bubbles are then absorbed by the large bubble residing above the heater surface, which acts as a reservoir. After absorption the heater surface is rewetted and the cycle is repeated. The enhancement of boiling heat transfer in microgravity is attributed to this sequence of events. Abe et al.' and Straub et al. ${ }^{13}$ have attempted to describe the heat transfer with pool boiling in microgravity in terms of Marangoni convection. However, the present vapor bubble motion described above appears to be so vigorous that any contributions by Marangoni convection to the heat transfer would be overshadowed. If the Marangoni convection were indeed a significant force, the vapor bubble would be impelled toward the heater surface because of the temperature gradient. No comparisons were possible between the mean heat transfer coefficient in microgravity, about $1000 \mathrm{~W} / \mathrm{m}^{2} \cdot \mathrm{K}$ at $\mathrm{a} / \mathrm{g}=10^{-4}$ in Figure 9 , and in earth gravity at $\mathrm{a} / \mathrm{g}=+1$ because nucleation did not occur at the low heat flux level of $2 \mathrm{~W} / \mathrm{cm}^{2}$. It was observed that the bubble motions become more vigorous in microgravity as the heat flux increases, as also occurs in earth gravity.

\section{Heater Surface Dry Fraction}

The computed mean heat transfer coefficient is quite sensitive to changes in the mean heater surface temperature, as can be noted in Figure 9, and after viewing the photographs of the boiling process from the heater underside the question arises as to whether a direct relationship exists between changes in the heater surface temperature and the heater surface dry fraction, that portion of the heater surface not wet. During those intervals when a distinct portion of the heater surface was dry, the dry area was measured frame by frame using an image process software, from which the heater surface dry fraction was determined. Measurements of the dry ratio for STS-57 Run \#3, whose data and photographs are given in Figures 9 and 10, are plotted in Figure 11 over the time interval of 33-60 seconds along with the corresponding mean heater surface temperature. It is noted that a direct correspondence exists between the variation of the mean heater surface temperature and the dry ratio. As a result, the increase in the mean heater surface temperature taking place over the time interval of 35-43 seconds in Figure 11 can be attributed directly to the increase in partial dry out of the heater surface.

From detailed analysis of the 27 test runs conducted in microgravity in the three space experiments to this point, quasi-steady nucleate boiling always took place for the cases in which the two lower heat flux levels of 2 and $4 \mathrm{~W} / \mathrm{cm}^{2}$ and the high subcooling level of $11{ }^{\circ} \mathrm{C}$ were present. Transient dryout always occurred at the high heat flux level of $8 \mathrm{~W} / \mathrm{cm}^{2}$ at all levels of subcooling used here. A representative case of transient dryout in microgravity is shown in Figure 12, together with the steady nucleate boiling in earth gravity for similar conditions in STS-60 Run \#4. At the high heat flux level of $6.5 \mathrm{~W} / \mathrm{cm}^{2}$ and subcooling $3.2^{\circ} \mathrm{C}$ the mean heater surface superheat in microgravity increases to about $160^{\circ} \mathrm{C}$ at 45 seconds, while in earth gravity the 


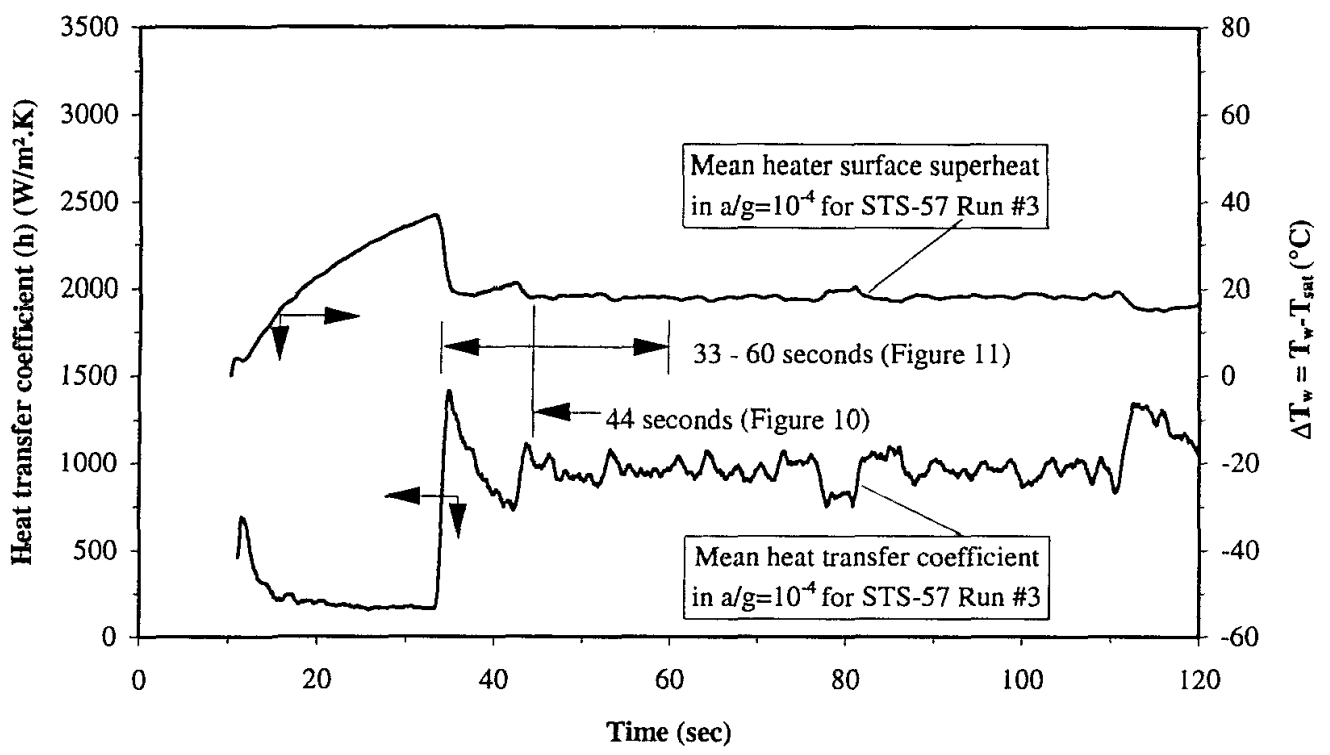

Figure 9. Measured mean heater surface temperature and derived heat transfer coefficient for STS-57 Run \#3. $\mathrm{a} / \mathrm{g}=10^{-4}, \mathrm{t}^{*}=23.63 \mathrm{sec} ., q_{T}^{\prime \prime}=2.0 \mathrm{~W} / \mathrm{cm}^{2}, \mathrm{P}_{\mathrm{sys}}=149.3 \mathrm{kPa}, \mathrm{T}_{\text {sat }}=59.7^{\circ} \mathrm{C}, \mathrm{T}_{\text {bulk }}=48.7^{\circ} \mathrm{C}, \mathrm{T}_{\mathrm{w}}=78{ }^{\circ} \mathrm{C}, \Delta \mathrm{T}_{\mathrm{w}}=18.3^{\circ} \mathrm{C}$, $\Delta \mathrm{T}_{\mathrm{sub}}=11.5^{\circ} \mathrm{C}$.

steady boiling results in a heat transfer coefficient of about $2400 \mathrm{~W} / \mathrm{m}^{2} \cdot \mathrm{K}$. On considering all tests in microgravity it is determined that dryout (or CHFcritical heat flux) for R-113 occurs at heat flux levels between $6.5 \mathrm{~W} / \mathrm{m}^{2} \cdot \mathrm{K}$ and $3.6 \mathrm{~W} / \mathrm{m}^{2} \cdot \mathrm{K}$.

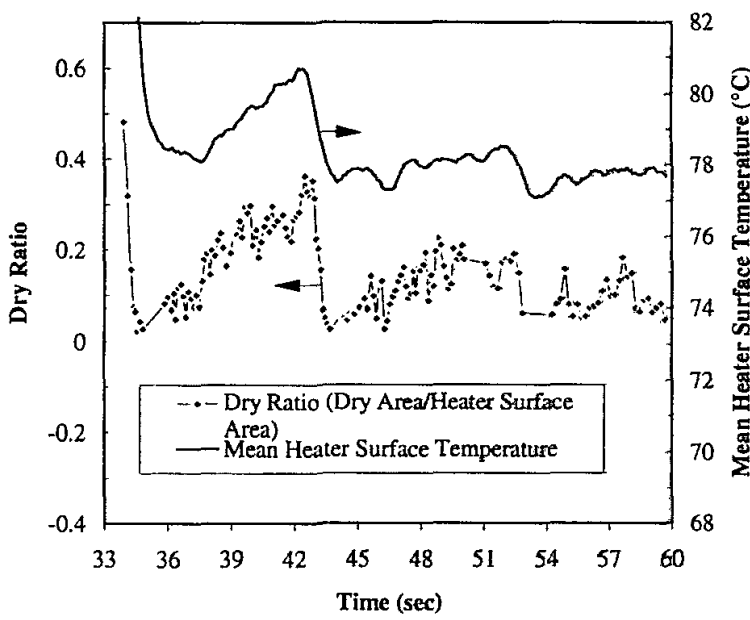

Figure 11. Heater surface dry fraction and mean heater surface temperature correlation for STS-57 Run \#3.

Of the total of 12 test runs at both the two lower levels of subcooling and the two lower levels of heat flux, 7 test runs randomly were in a state that can be classified as quasi-steady nucleate boiling, which is indicative of the presence of instabilities in the process. The large bubble initially formed on the heater surface either moved away from the heater surface or remained attached, producing partially dryout of the surface, depending on the intensity of the initial dynamic vapor bubble growth. As discussed previously, the large bubble then can serve as a reservoir to absorb and remove the bubbles generated at the heater surface, and permit the heater surface to be maintained in a wetted condition, producing in turn the quasi-steady nucleate boiling, even with low levels of subcooling. In this latter case the large bubble continuously grows, giving rise to subsequent effects associated with the system geometry. A typical test run at both a lower level of subcooling $\left(0.8^{\circ} \mathrm{C}\right)$ and heat flux $\left(1.8 \mathrm{~W} / \mathrm{m}^{2}\right)$ is illustrated in Figure 13. The mean heater surface superheat is quite steady, even with a low subcooling close to saturation. Steady boiling appears to be possible in principle, with a saturated liquid, provided that a large bubble remains in residence near the heater surface such that a sufficient flow of liquid would still take place to all parts of the heater surface. This latter requirement would probably place an upper limit on the size of a flat heater surface that could sustain nucleate pool boiling in microgravity. The superheat increase taking place at about 80 seconds in Figure 13 is a consequence of the large bubble making contact with the opposite wall of the test vessel and forcing contact with the heater surface. The resulting heater surface dryout then causes the increase in mean heater surface superheat. 
Copyright (C)1996, American Institute of Aeronautics and Astronautics, Inc.

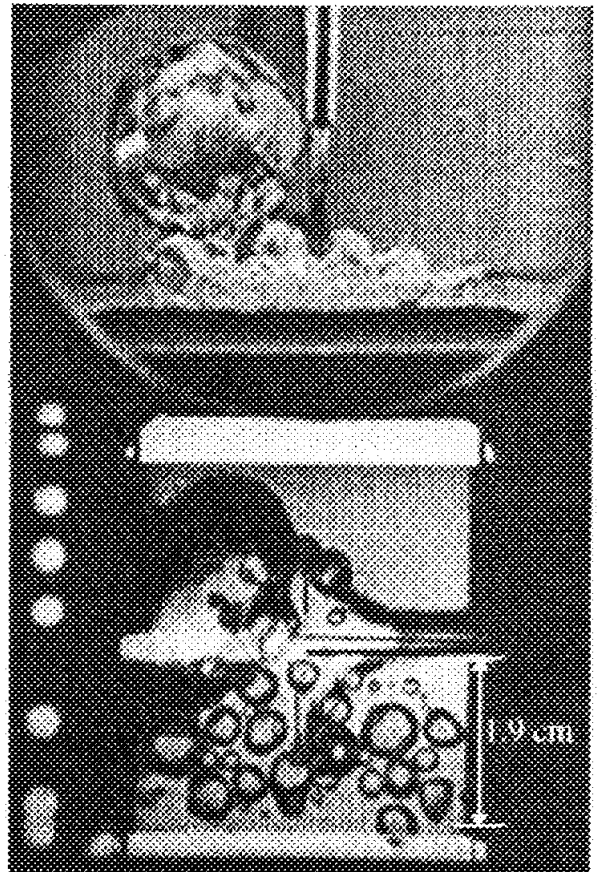

(A) time $=44.16 \mathrm{sec}$.

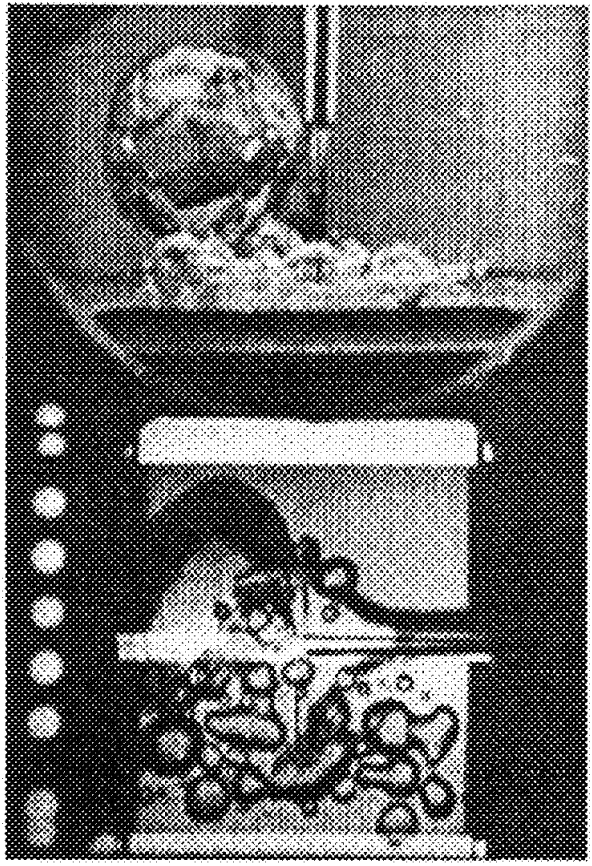

(C) time $=44.20 \mathrm{sec}$.

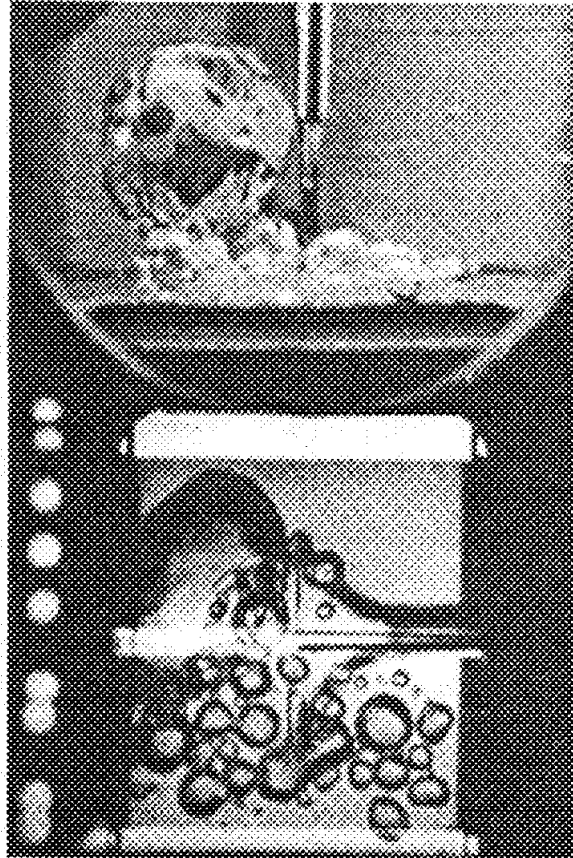

(B) time $=44.18 \mathrm{sec}$.

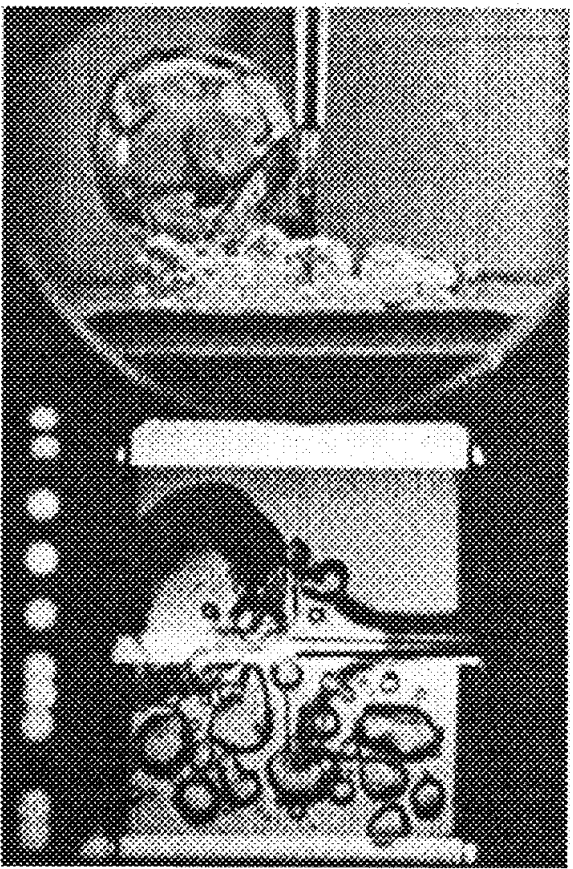

(D) time $=44.22 \mathrm{sec}$.

Figure 10. Vapor bubble coalescence for STS-57 Run \#3. $\mathrm{a} / \mathrm{g}=10^{-4}, q_{T}^{\prime \prime}=2.0 \mathrm{~W} / \mathrm{cm}^{2}, \mathrm{P}_{\mathrm{sys}}=149.3 \mathrm{kPa}, \mathrm{T}_{\mathrm{sal}}=59.7^{\circ} \mathrm{C}$, $\mathrm{T}_{\text {bulk }}=48.7^{\circ} \mathrm{C}, \mathrm{T}_{\mathrm{w}}=78^{\circ} \mathrm{C}, \Delta \mathrm{T}_{\mathrm{w}}=18.3^{\circ} \mathrm{C}, \Delta \mathrm{T}_{\text {sub }}=11.5^{\circ} \mathrm{C}$. 


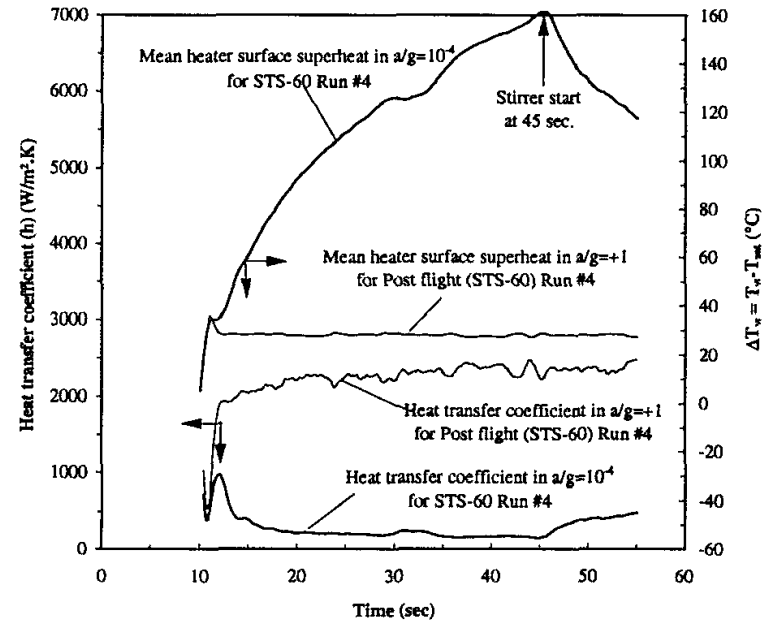

Figure 12. Comparison of measured mean heater surface superheat and derived heat transfer coefficient between space flight STS-60 Run \#4 $\left(\mathrm{a} / \mathrm{g}=10^{-4}\right)$ and Post flight (STS-60) Run \#4 ( $/ \mathrm{g}=+1)$.

Space flight (STS-60) Run \#4: $\mathrm{a} / \mathrm{g}=10^{-4}, \mathrm{t}^{*}=0.74 \mathrm{sec}$., $q_{T}^{\prime \prime}=6.5 \mathrm{~W} / \mathrm{cm}^{2}, \mathrm{P}_{\text {sys }}=117.3 \mathrm{kPa}, \mathrm{T}_{\text {sat }}=52.0^{\circ} \mathrm{C}, \mathrm{T}_{\text {bulk }}=$ $48.8^{\circ} \mathrm{C}, \mathrm{T}_{\mathrm{w}}=$ dryout, $\Delta \mathrm{T}_{\mathrm{w}}=$ dryout, $\Delta \mathrm{T}_{\mathrm{sub}}=3.2^{\circ} \mathrm{C}$.

Post flight (STS-60) Run \#4: $\mathrm{a} / \mathrm{g}=+1, \mathrm{t}^{*}=0.76 \mathrm{sec}$., $q_{T}^{\prime \prime}=7.0 \mathrm{~W} / \mathrm{cm}^{2}, \mathrm{P}_{\text {sys }}=114.1 \mathrm{kPa}, \mathrm{T}_{\text {sal }}=51.1^{\circ} \mathrm{C}, \mathrm{T}_{\text {bulk }}=47.9$ ${ }^{\circ} \mathrm{C}, \mathrm{T}_{\mathrm{w}}=79.1^{\circ} \mathrm{C}, \Delta \mathrm{T}_{\mathrm{w}}=28{ }^{\circ} \mathrm{C}, \Delta \mathrm{T}_{\mathrm{sub}}=3.2^{\circ} \mathrm{C}$.

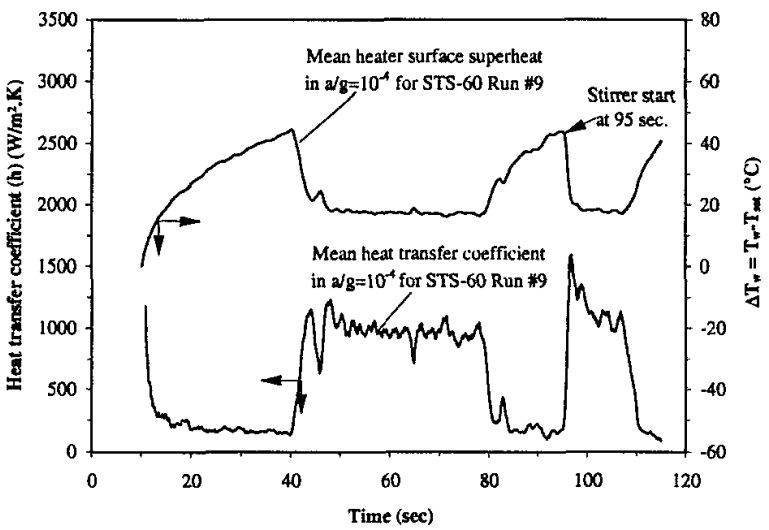

Figure 13. Measured mean heater surface superheat and derived heat transfer coefficient for space flight

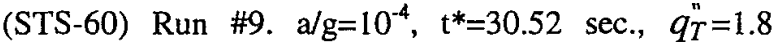
$\mathrm{W} / \mathrm{cm}^{2}, \mathrm{P}_{\text {sys }}=107.7 \mathrm{kPa}, \mathrm{T}_{\text {sal }}=49.4{ }^{\circ} \mathrm{C}, \mathrm{T}_{\text {bulk }}=48.6{ }^{\circ} \mathrm{C}$, $\mathrm{T}_{\mathrm{w}}=67.4^{\circ} \mathrm{C}, \Delta \mathrm{T}_{\mathrm{w}}=18^{\circ} \mathrm{C}, \Delta \mathrm{T}_{\mathrm{sub}}=0.8^{\circ} \mathrm{C}$.

Direct comparisons between nucleate pool boiling in quasi-steady operation at $\mathrm{a} / \mathrm{g}=+1$ and at microgravity with identical systems are given in Figure 14. Also included are the measurements of $\mathrm{Oker}^{10}$ obtained with $\mathrm{R}-113$ in a 1.4 second drop tower with $\mathrm{a} / \mathrm{g}<10^{-3}$, giving a fair agreement with the present data. A gold film

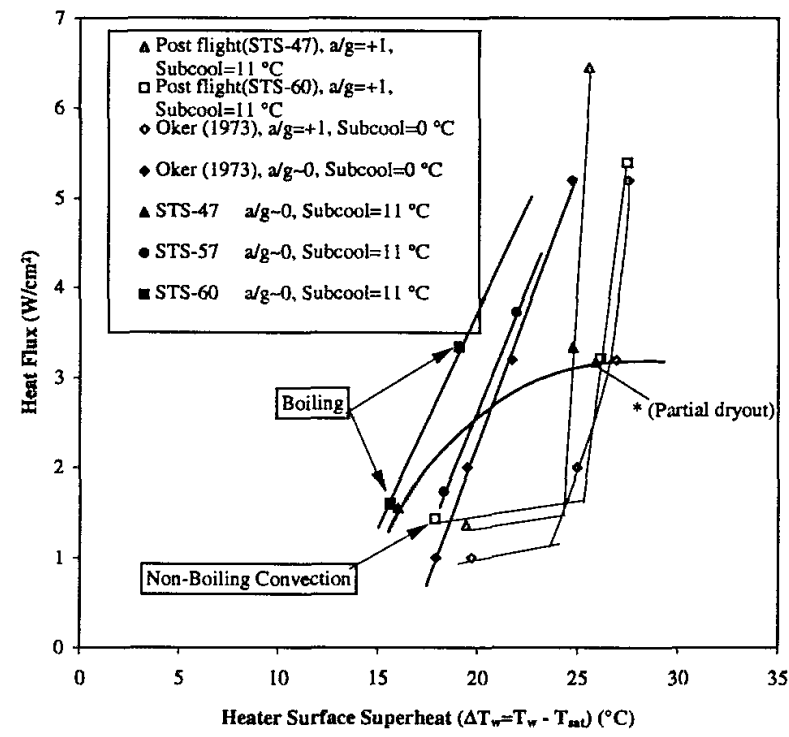

Figure 14. Direct comparisons of nucleate pool boiling of $\mathrm{R}-113$ between identical systems at $\mathrm{a} / \mathrm{g}=+1$ and microgravity conditions.

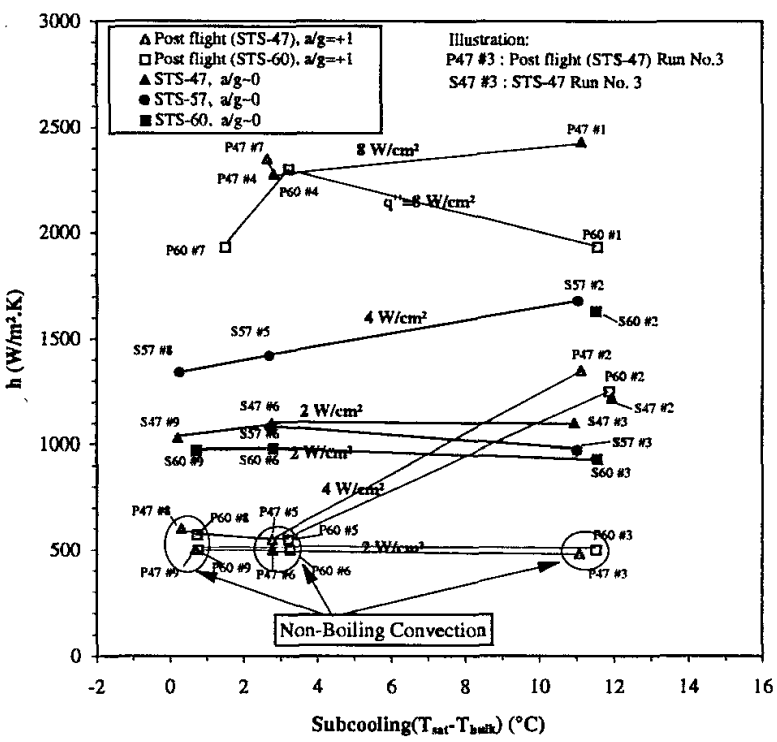

Figure 15. Total of heat transfer coefficient measurements obtained with STS-47-57-60 under quasisteady conditions, both $\mathrm{a} / \mathrm{g}=+1$ and microgravity.

heater similar to the present heater was used. It is clear in all cases here that a significant and reproducible degree of enhancement in the boiling process of about $30 \%$ takes place at the lower levels of heat flux with some degree of subcooling. Although the majority of test runs in which partial dryout was present produced transient boiling processes, one quasi-steady case existed with a partial dryout of about $25 \%$, and is so 


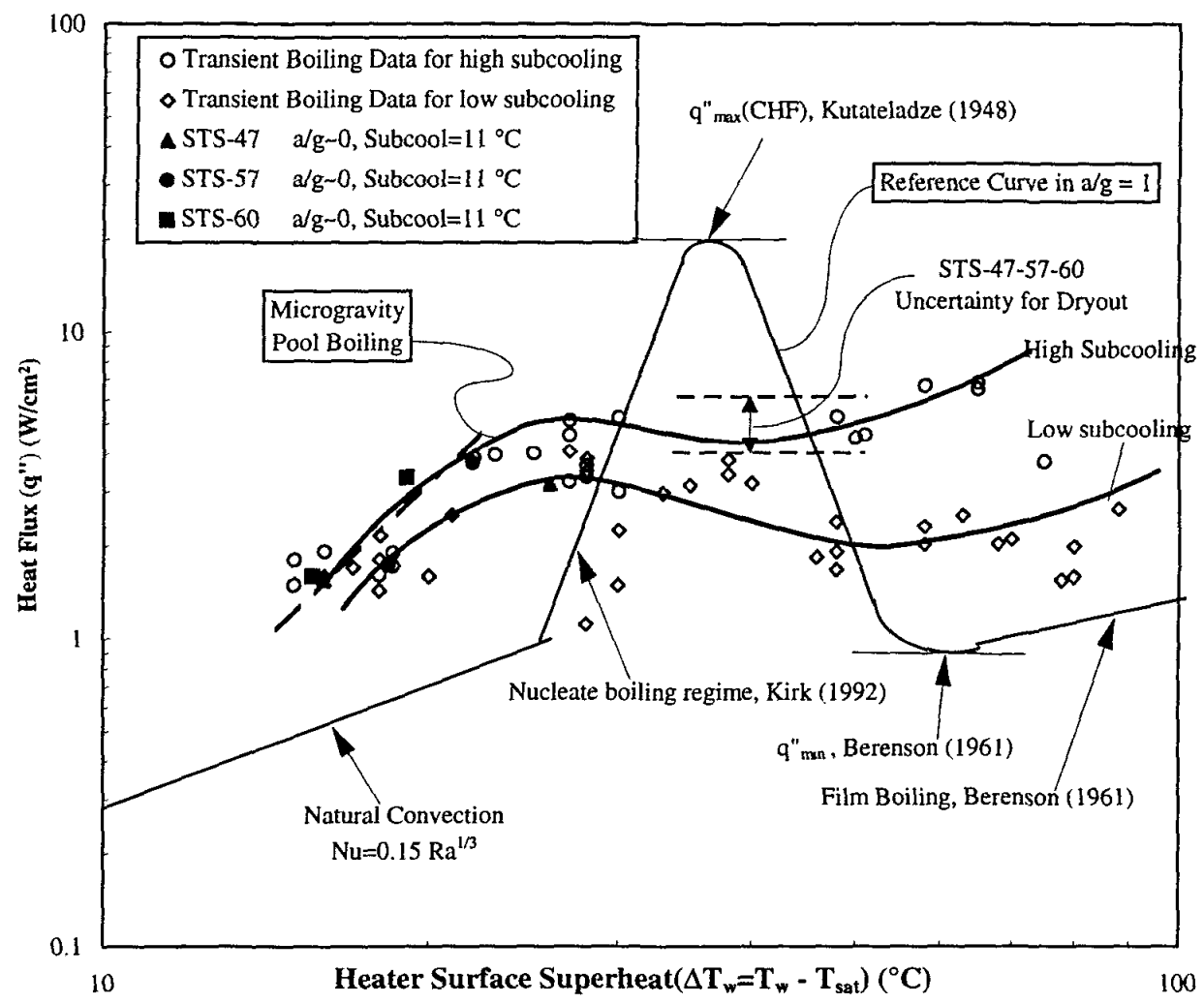

Figure 16. Approximate composite microgravity pool boiling curves for R-113 from steady and transient measurements on STS-47-57-60.

indicated in Figure 14. This occurred on STS-47 Run \#2 at a heat flux of $3.6 \mathrm{~W} / \mathrm{m}^{2}$ and $11^{\circ} \mathrm{C}$ subcooling, and resulted in an increased mean heater surface superheat to $26^{\circ} \mathrm{C}$ as shown.

\section{Subcooling Effects}

In order to illustrate more clearly how subcooling interacts with heat flux and buoyancy in influencing the overall heat transfer performance, the quasi-steady mean heat transfer coefficients are plotted in Figure 15 as a function of subcooling for the space flight hardware experiments only, both for $a / g=+1$ and in microgravity, with the total heat flux input as a parameter. It may be concluded that although subcooling has negligible influence on the microgravity heat transfer coefficient, increasing subcooling appears to increase the probability that steady boiling will take place.

The two conditions of $\mathrm{a} / \mathrm{g}=+1$ and microgravity are distinguished by the open versus dark data points. The distinction between non-boiling natural convection at $\mathrm{a} / \mathrm{g}=+1$, with $\mathrm{h}=500 \mathrm{~W} / \mathrm{m}^{2} \cdot \mathrm{K}$, and nucleate boiling in either $a / g=+1$ or microgravity becomes quite clear. At the highest level of heat flux of $8 \mathrm{~W} / \mathrm{cm}^{2}$ steady boiling takes place at $\mathrm{a} / \mathrm{g}=+1$ only, while at the lowest level of heat flux of $2 \mathrm{~W} / \mathrm{cm}^{2}$ only non-boiling convection occurs at a/g $=+1$, with steady nucleate boiling always taking place in microgravity.

The behavior at the intermediate level of heat flux of $4 \mathrm{~W} / \mathrm{cm}^{2}$ was quite inconsistent: at $\mathrm{a} / \mathrm{g}=+1$ nonboiling convection always took place at the lower levels of subcooling up to a subcooling of $4{ }^{\circ} \mathrm{C}$, but produced nucleate boiling when the subcooling was increased to $11^{\circ} \mathrm{C}$. This latter behavior is believed to be related to the effect of pressure on nucleation. Only in STS-57 did steady boiling occur in microgravity at an input heat flux level of $4 \mathrm{~W} / \mathrm{cm}^{2}$ for all levels of subcooling. For STS-47 and 60 steady boiling occurred only at the highest level of subcooling, with dryout taking place as the subcooling was decreased. 


\section{A Microgravity Pool Boiling Curve}

Sufficient information appears to be available at the present time to permit a somewhat speculative construction of an approximate microgravity pool boiling curve. Two such curves are shown in Figure 16, in which all available data for R-113 are plotted, including the quasi-steady or short term steady, and the slow transient, consisting of progressive dryout or rewetting. Also given in Figure 16 is a composite reference curve for pool boiling at earth gravity which was constructed using all available data and correlations, and seems to be reasonably representative of the circumstances present. The approximate composite microgravity pool boiling curve consists of two curves at this time; one for low levels of subcooling and the other for the higher level of subcooling used here, which bear some resemblance to the Reference Curve, albeit over a wider spread in the heater surface superheat. The uncertainty of the heat flux at which dryout takes place is estimated to be within the range of $4-6 \mathrm{~W} / \mathrm{cm}^{2}$, as shown in Figure 16.

It should be pointed out finally that pool boiling with fluids whose wetting characteristics are unlike that of R-113, and with surfaces' different from the highly polished quartz used, could produce behavior different from that described here.

\section{Conclusions}

It appears that long term steady state nucleate boiling can take place on a flat heater surface in microgravity with a wetting liquid under conditions in which a large vapor bubble somewhat removed from the heater surface is formed, which acts as a reservoir to remove the bubbles from immediate vicinity of the heater surface. The steady nucleate boiling heat transfer is significantly enhanced in microgravity compared to that in earth gravity.

Surface tension has an important role in producing dryout and/or rewetting on a heated surface. The detailed circumstances describing this remain to be explored further, but the heat flux at which dryout occurs is considerably less in microgravity than in earth gravity.

Using the quasi-steady data obtained during the periods in which some significant portions of the heater surface were dried out it was possible to construct two distinct composite approximate microgravity pool boiling curves for R-113, one for the higher level of subcooling and one for the lower level of subcooling. This is compared with a Reference Curve for pool boiling at $\mathrm{a} / \mathrm{g}=+1$, constructed from all available data and correlations deemed to reasonably represent the circumstances present. The microgravity pool boiling curves bear some resemblance to the Reference Curve, although the maximum heat flux (critical heat flux) and the minimum (film boiling) heat flux is also reduced considerably.

\section{Acknowledgment}

This work was supported with appreciation under NASA Contract NAS 3-25812.

\section{References}

1. Abe, Y., Oka, T., Mori, Y.H., and Nagashima, A., 1994, "Pool Boiling of a Non-Azeotropic Binary Mixture under Microgravity", Int. J. Heat Mass Transfer, Vol.37, No.16, pp.2405-2413.

2. Berenson, P.J., 1961, "Film Boiling Heat Transfer from a Horizontal Surface", J. Heat Transfer, Vol.83, pp.351.

3. Ervin, J.S., Merte, Jr., H., Keller, R.B., and Kirk, K., 1992 "Transient Pool Boiling in Microgravity", Int. J. Heat Mass Transfer, Vol.35, No.3, pp.659674.

4. Kirk, K.M., 1992, "A Study of the Relative Effects of Buoyancy and Liquid Momentum in Forced Convection Nucleate Boiling", Ph.D. Thesis, The university of Michigan.

5. Kutateladze, S.S., 1948, "On the Transition to Film Boiling under Natural Convection", Kotloturbostroenie, No. 3, pp.10.

6. Littles, J.W., and Walls, H.A., 1970, "Nucleate Pool Boiling of Freon 113 at Reduced Gravity Levels", Proc. Fluid. Eng., Heat Transfer and Lubr. Conference, 70-HT-17

7. Merte, Jr. H. and Clark, J.A., 1964, "Boiling Heat Transfer with Cryogenic Fluid at Standard, Fractional, and Near-Zero Gravity", Journal of Heat Transfer, Vol.86C,pp.315-319.

8. Merte, Jr. H., Lee, H.S., and Ervin, J.S., 1994, "Transient Nucleate Pool Boiling in MicrogravitySome Initial Results", Microgravity sci. technol. Vol. VIJ/2, pp.173-179.

9. Merte, Jr. H., Lee, H.S. and Keller, R.B., 1995, "Report on Pool Boiling Experiment Flown on STS-47-57-60", Report No.UM-MEAM-95-01, Department of Mechanical Engineering and Applied Mechanics, The University of Michigan, Ann Arbor, Michigan, NASA Contract NAS 325812 .

10. Oker, E., 1973, "Transient Boiling Heat Transfer in Saturation Liquid Nitrogen and R113 at Standard and Zero Gravity", Ph.D. Thesis, The university of Michigan.

11. Siegel, R. and Keshock, E.G., 1964, "Effects of Reduced Gravity on Nucleate Boiling Bubble Dynamics in Saturated Water", A.I.Ch.E. Journal, Vol. 10, No.4, pp.509-517 
12. Siegel, R. and Usiskin C., 1959, "A photographic Study of Boiling in the Absence of Gravity", Journal of Heat Transfer, Trans. ASME, Series C, Vol.81, pp.230-236.

13. Straub, J., Zell, M., and Vogel, B., 1990, "Pool Boiling in a Reduced Gravity Field", Proceedings of The Ninth International Heat Transfer Conference, Jerusalem, Israel, Vol.1, pp.91-112.

14. Straub, J., Winter, J., Picker, G., Merte, H., and Kono, A., 1992, "Study of Vapor Bubble Growth in a Supersaturated Liquid", 8th European Symposium on Materials and Fluid Science in Microgravity, Brussels, Belgium, April, pp.12-16.

15. Usiskin, C.M. and Siegel, R., 1961, "An Experimental Study of Boiling in Reduced and Zero Gravity Fields", Journal of Heat Transfer, Vol.83, No.3, pp.243-253. 


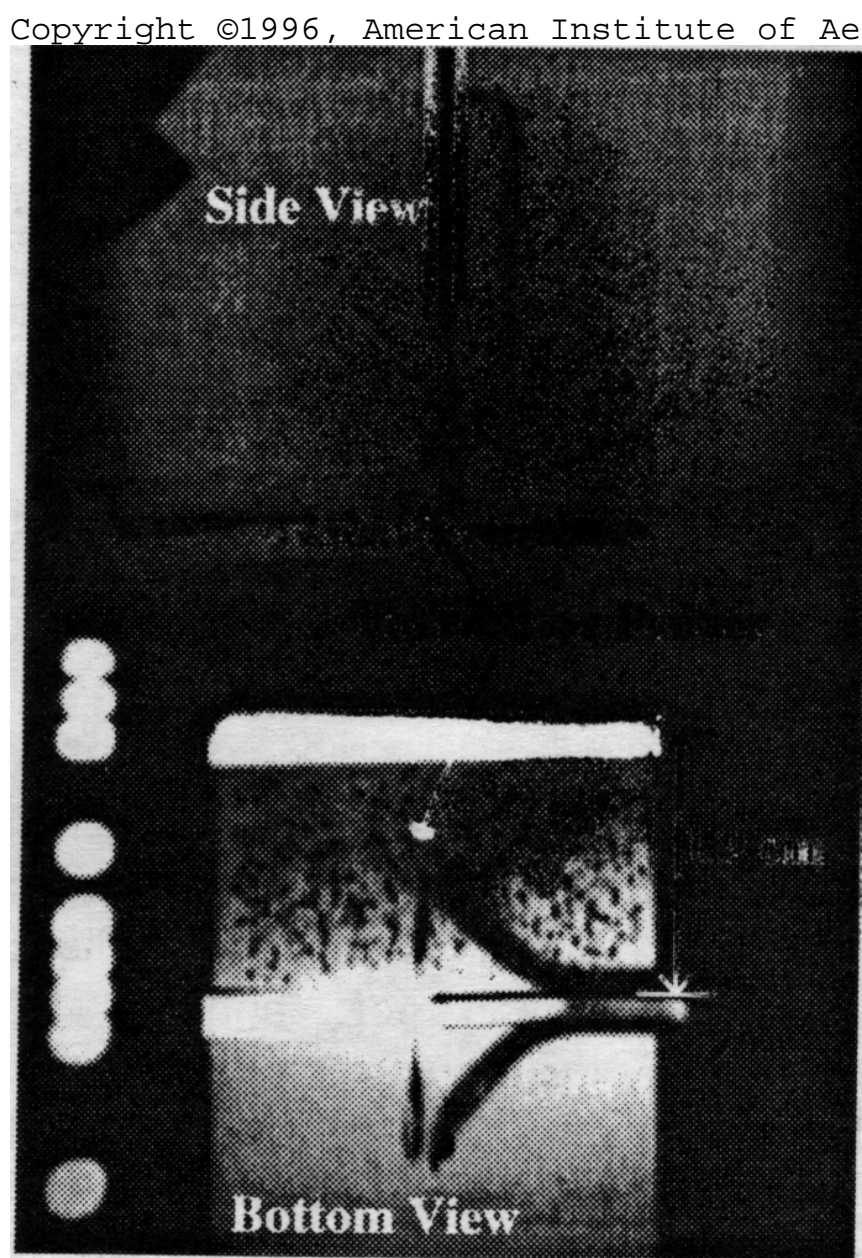

(a) Normal gravity $\mathrm{a} / \mathrm{g}=+1(\mathrm{t}=78.22 \mathrm{sec}$. $)$

Post flight (STS-60) Run \#2 $q_{T}^{\prime \prime}=3.6 \mathrm{~W} / \mathrm{cm}^{2}$, Psys $=150.1 \mathrm{kPa}$, $\Delta \mathrm{T}_{\mathrm{w}}=27^{\circ} \mathrm{C}, \Delta \mathrm{T}_{\mathrm{sub}}=11.5^{\circ} \mathrm{C}$.

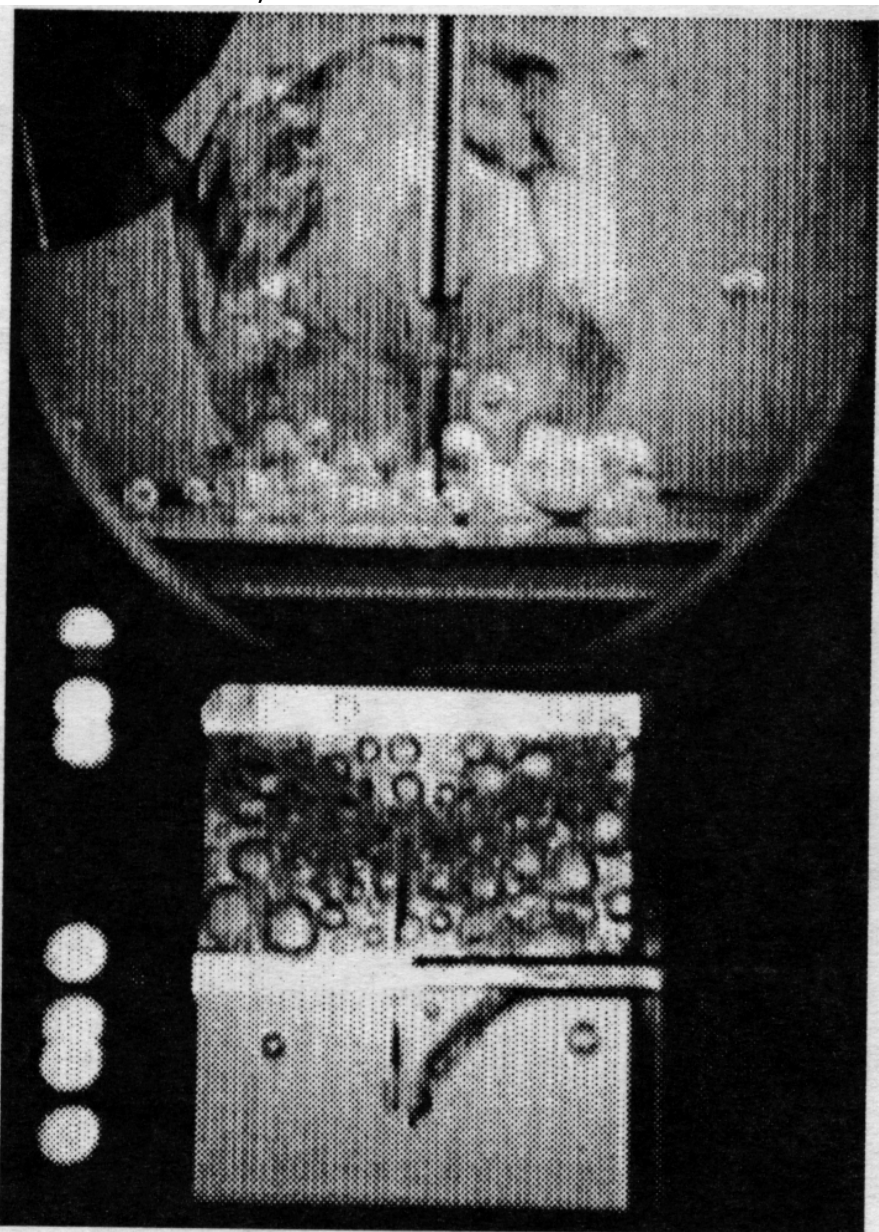

(b) Reduced gravity $\mathrm{a} / \mathrm{g}=10^{-4}(\mathrm{t}=61.47 \mathrm{sec})$

Space flight (STS-60) Run \#2.

$q_{T}^{\prime \prime}=3.6 \mathrm{~W} / \mathrm{cm}^{2}$, Psys $=145.9 \mathrm{kPa}$, $\Delta \mathrm{T}_{\mathrm{w}}=18.1^{\circ} \mathrm{C}, \Delta \mathrm{T}_{\mathrm{sub}}=11.5^{\circ} \mathrm{C}$. 
Copyright (01996, American Institute of Aeronautics and Astronautics, Inc.

Fig. 5

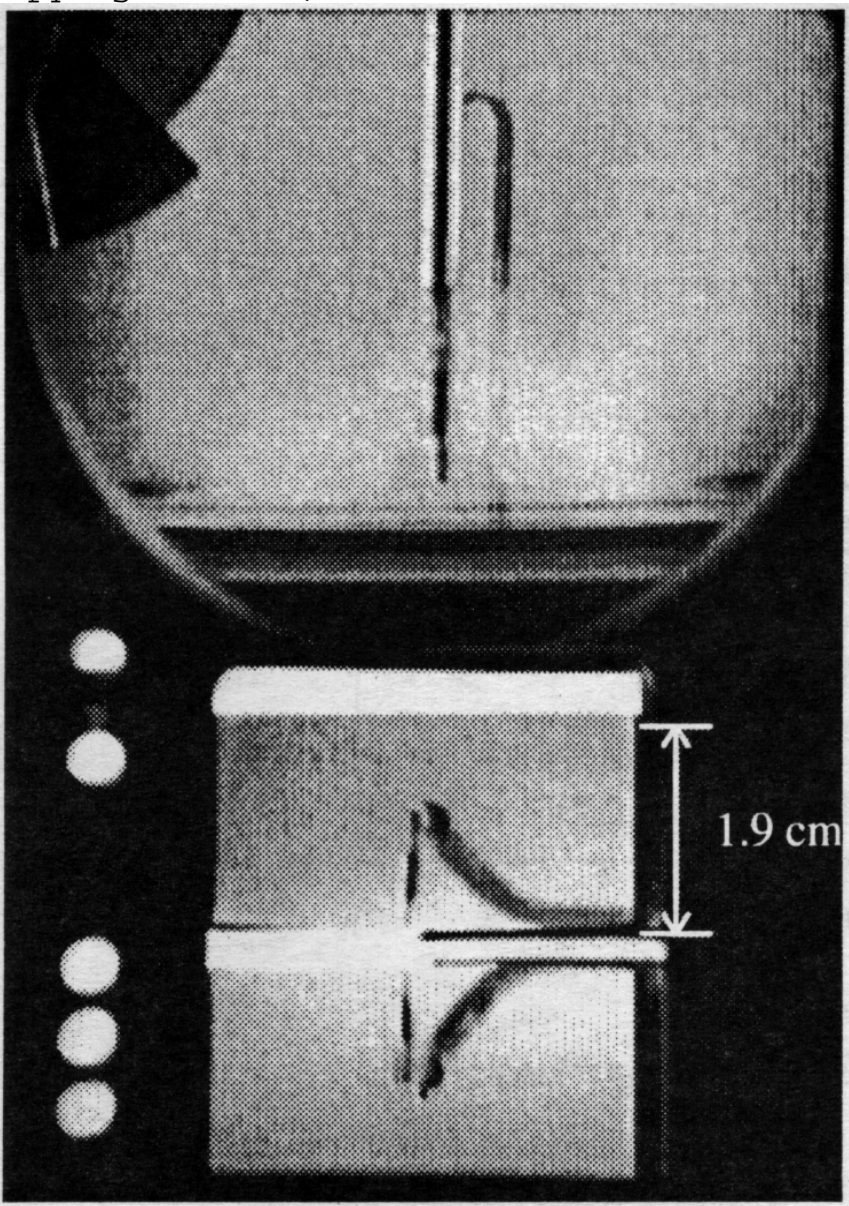

(A) time $=30.85 \mathrm{sec}$.

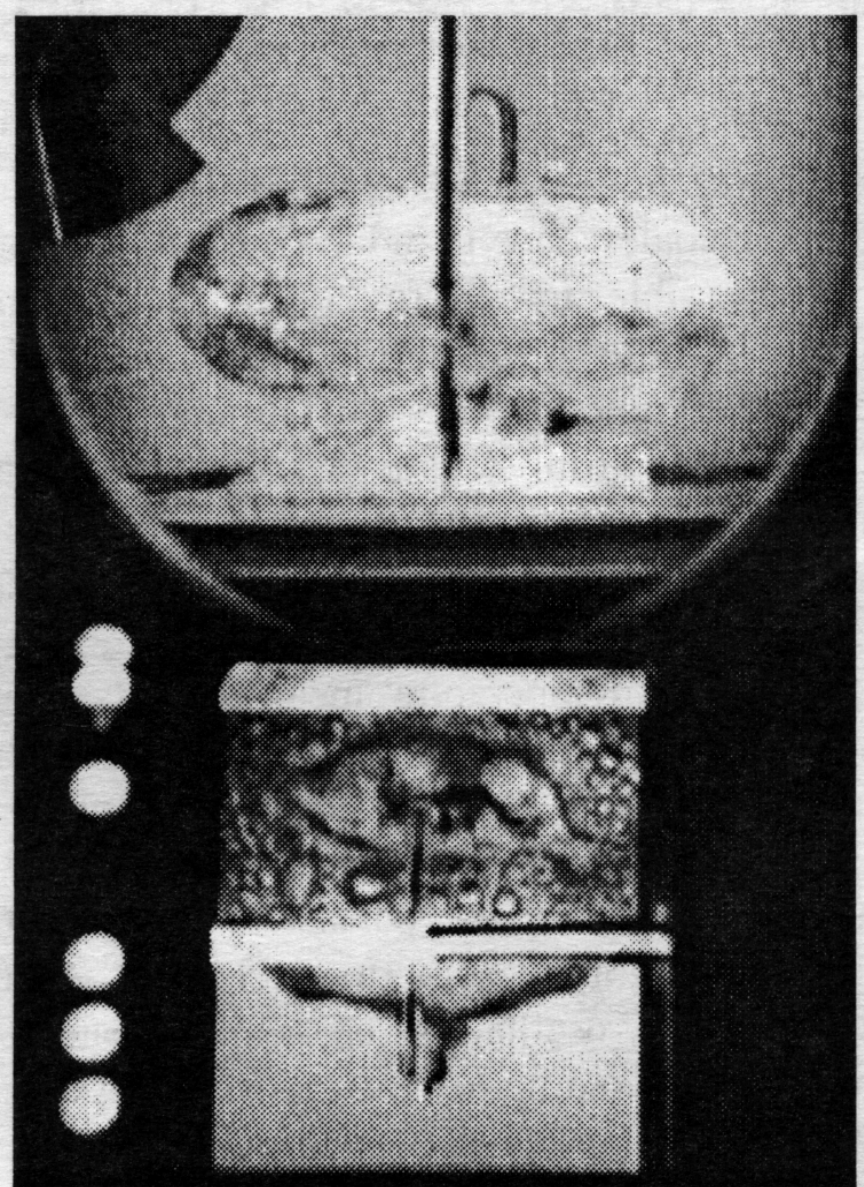

(C) time $=31.25 \mathrm{sec}$.

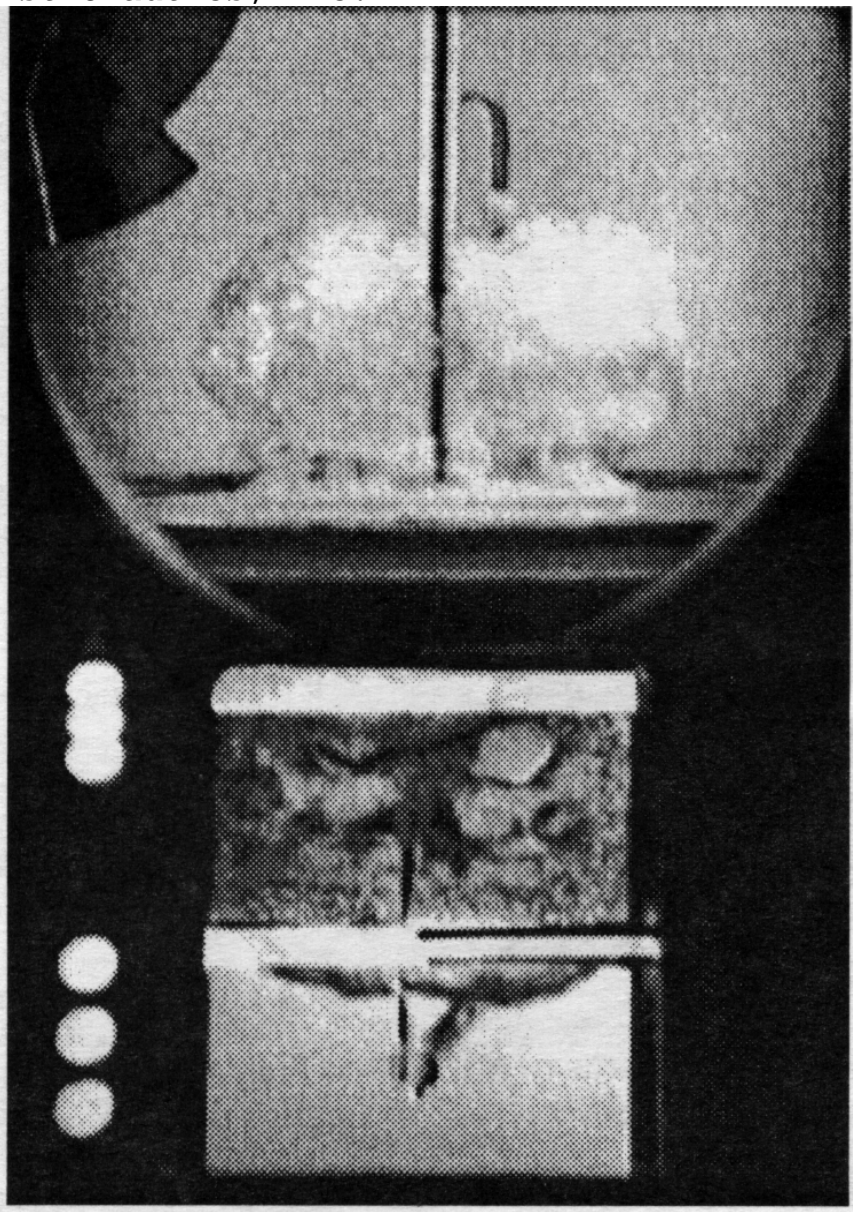

(B) time $=31.05 \mathrm{sec}$.

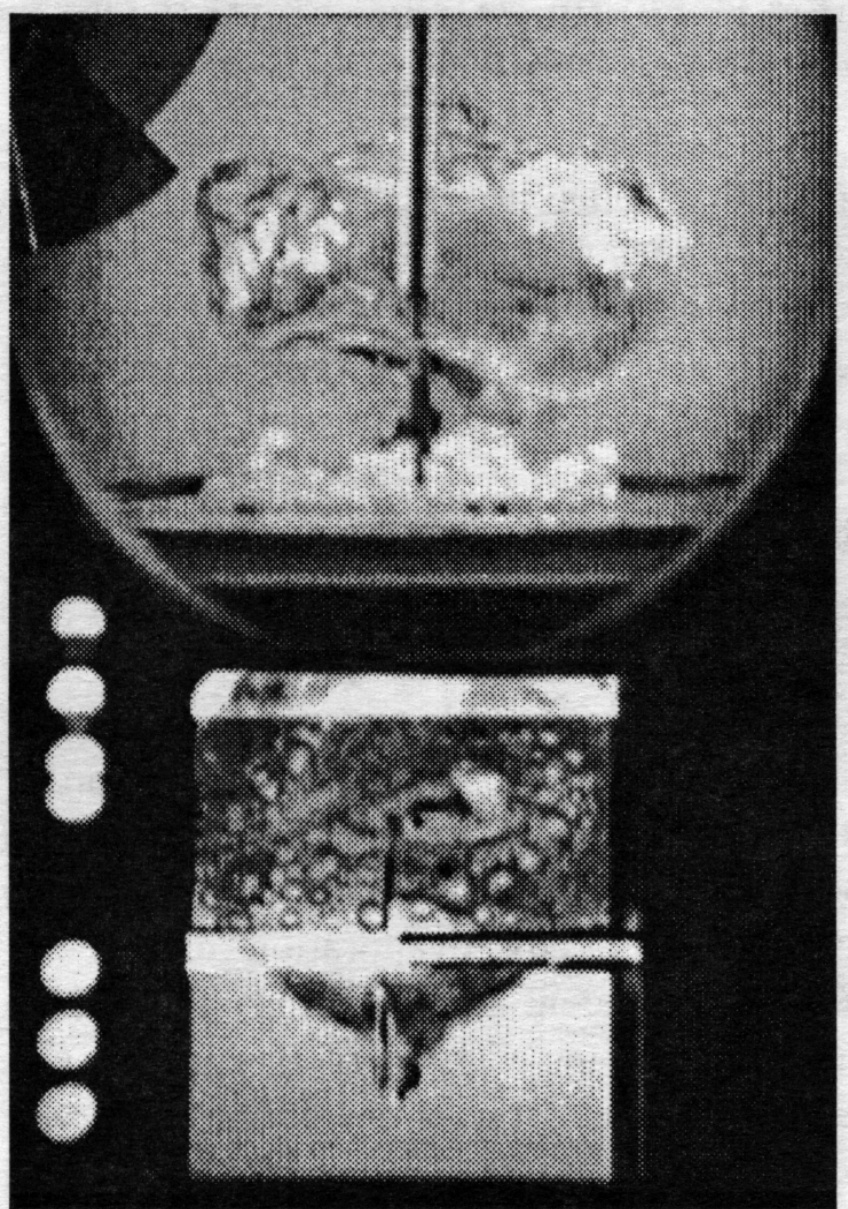

(D) time $=31.55 \mathrm{sec}$. 
Copyright 01996, American Institute of Aeronautics and Astronautics, Inc.

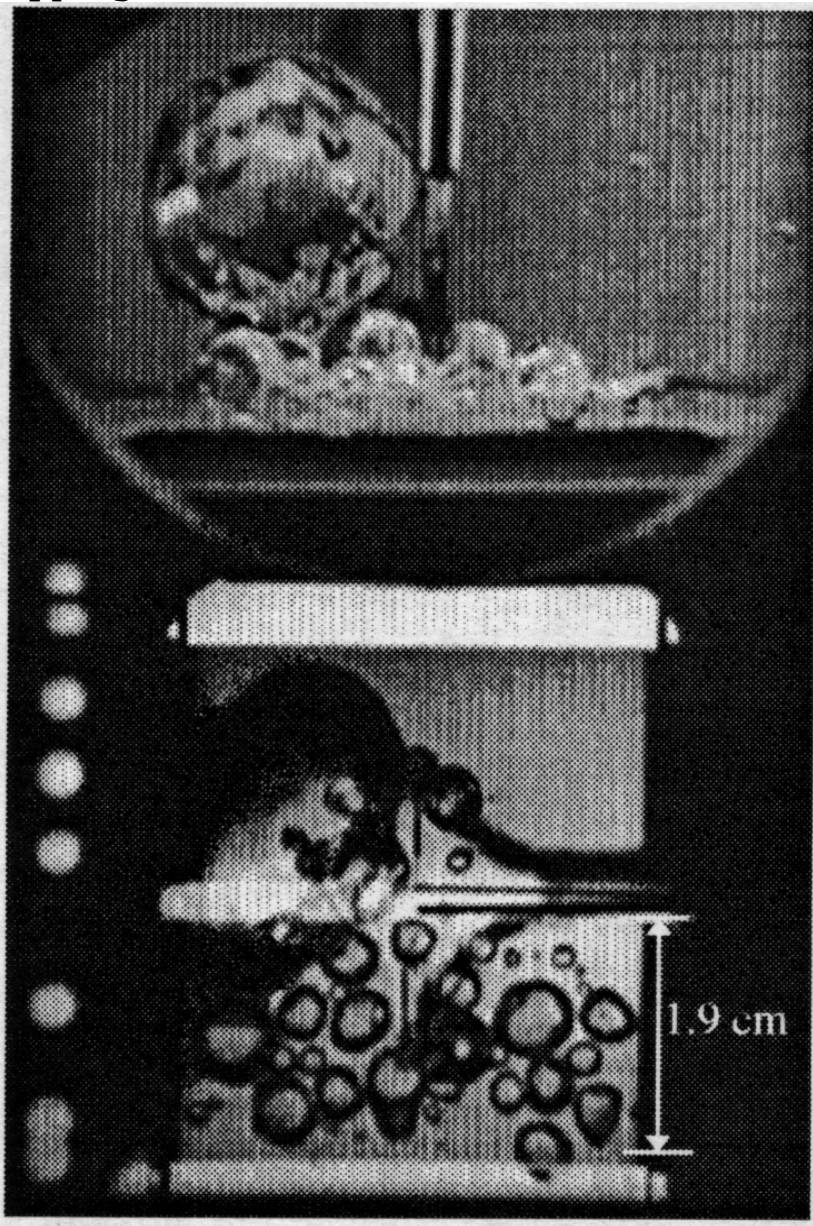

(A) time $=44.16 \mathrm{sec}$.

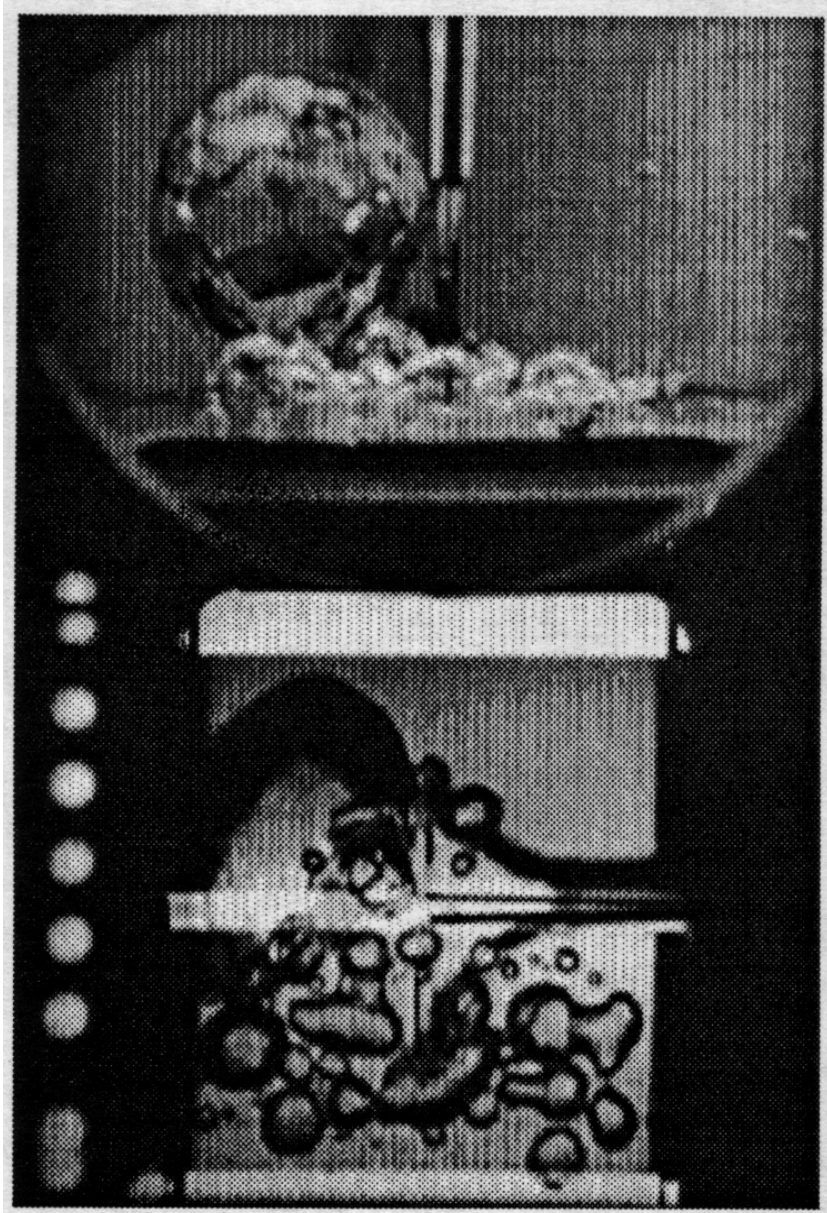

(C) time $=44.20 \mathrm{sec}$.

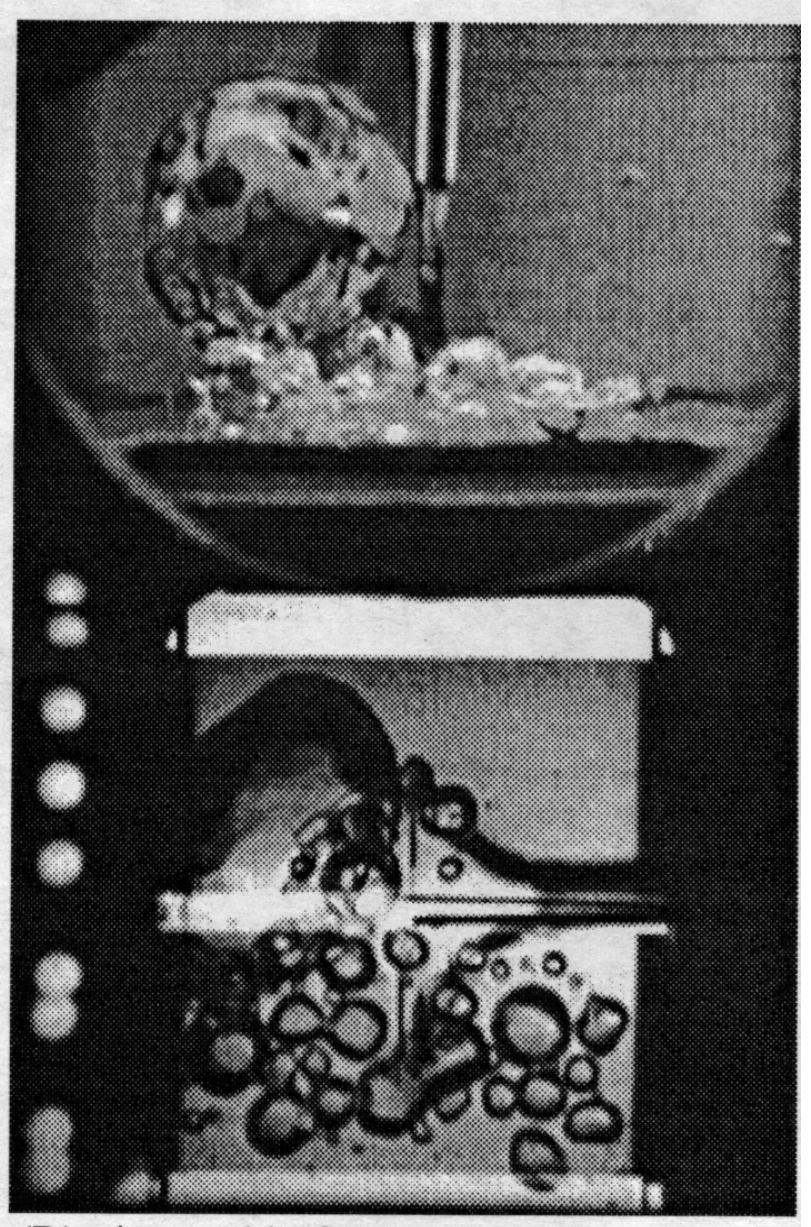

(B) time $=44.18 \mathrm{sec}$.

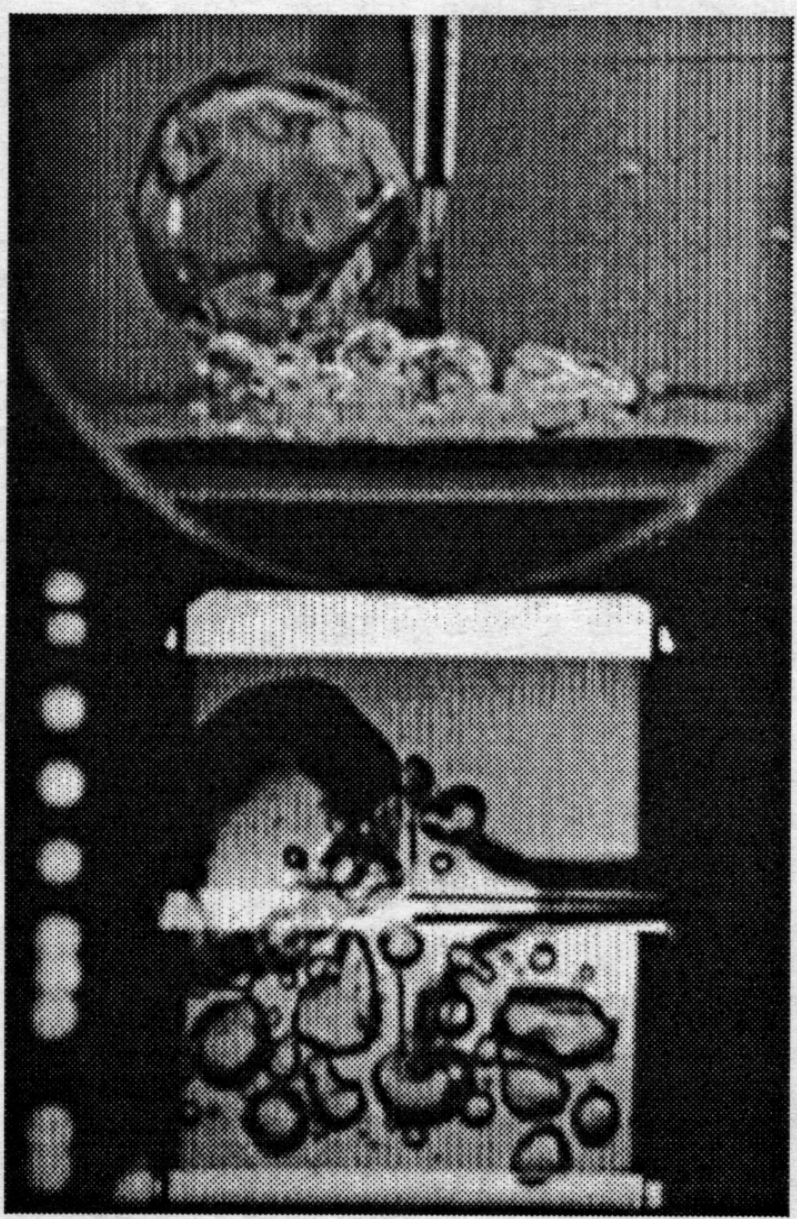

(D) time $=44.22 \mathrm{sec}$. 